\title{
Evaluation of Planetary Boundary Layer Simulation in GFDL Atmospheric General Circulation Models
}

\author{
HyeyUM HAILEY SHIN \\ Cooperative Programs for the Advancement of Earth System Science, University Corporation for Atmospheric \\ Research, Boulder, Colorado, and NOAA/Geophysical Fluid Dynamics Laboratory, Princeton, New Jersey \\ Yi MING AND MING ZHAO \\ NOAA/Geophysical Fluid Dynamics Laboratory, Princeton, New Jersey \\ JEAN-CHRISTOPHE GOLAZ \\ Lawrence Livermore National Laboratory, Livermore, California \\ BAOQIANG XiAng AND HuAn GuO \\ Cooperative Programs for the Advancement of Earth System Science, University Corporation for Atmospheric \\ Research, Boulder, Colorado, and NOAA/Geophysical Fluid Dynamics Laboratory, Princeton, New Jersey
}

(Manuscript received 11 August 2017, in final form 2 March 2018)

\begin{abstract}
This study describes the performance of two Geophysical Fluid Dynamics Laboratory (GFDL) atmospheric general circulation models (AGCMs) in simulating the climatologies of planetary boundary layer (PBL) parameters, with a particular focus on the diurnal cycles. The two models differ solely in the PBL parameterization: one uses a prescribed K-profile parameterization (KPP) scheme with an entrainment parameterization, and the other employs a turbulence kinetic energy (TKE) scheme. The models are evaluated through comparison with the reanalysis ensemble, which is generated from European Centre for MediumRange Weather Forecasts (ECMWF) twentieth-century reanalysis (ERA-20C), ERA-Interim, NCEP CFSR, and NASA MERRA, and the following systematic biases are identified. The models exhibit widespread cold biases in the high latitudes, and the biases are smaller when the KPP scheme is used. The diurnal cycle amplitudes are underestimated in most dry regions, and the model with the TKE scheme simulates larger amplitudes. For the near-surface winds, the models underestimate both the daily means and the diurnal amplitudes; the differences between the models are relatively small compared to the biases. The role of the PBL schemes in simulating the PBL parameters is investigated through the analysis of vertical profiles. The Sahara, which is suitable for focusing on the role of vertical mixing in dry PBLs, is selected for a detailed analysis. It reveals that compared to the KPP scheme, the heat transport is weaker with the TKE scheme in both convective and stable PBLs as a result of weaker vertical mixing, resulting in larger diurnal amplitudes. Lack of nonlocal momentum transport from the nocturnal low-level jets to the surfaces appears to explain the underestimation of the near-surface winds in the models.
\end{abstract}

\section{Introduction}

The planetary boundary layer (PBL) is the lowest part of the troposphere that responds to surface forcing at a time scale of an hour or less (Stull 1988). Modulated by insolation, the PBL over land generally undergoes pronounced diurnal cycles in sync with the surface, and this

Corresponding author: Hyeyum Hailey Shin, hyeyum.shin@ noaa.gov strong surface coupling distinguishes the PBL from the free troposphere (FT; cf. Stull 1988; Garratt 1992; Hartmann 1994; Arya 2001; Wyngaard 2010). The exchanges of momentum, heat, moisture, and chemical constituents between the surface and the FT take place in the PBL, and are not explicitly resolved at typical spatial resolutions of global weather and climate models (from $\sim 10$ to $\sim 100 \mathrm{~km}$ ). Since the subgrid-scale vertical transport in the PBL has a profound influence on the weather and climate systems (by altering surface fluxes, cloud 
processes, convection, air quality, etc.), an accurate representation of the turbulent transport is essential for reliable weather and climate simulations. Despite continuous efforts to improve the PBL parameterization, correctly simulating the vertical structures of the PBL and their diurnal variations remains challenging for state-of-the-art weather and climate models (Teixeira et al. 2008; Svensson et al. 2011; Holtslag et al. 2013).

A number of previous studies evaluated the performance of numerical weather prediction (NWP) models or regional climate models (RCMs) in simulating the diurnal cycles of PBL parameters, such as referencelevel temperature (normally at $2 \mathrm{~m}$ above the ground) and wind speed (normally at $10 \mathrm{~m}$ ), surface fluxes, PBL height, and precipitation (e.g., Betts and Jakob 2002; Zhang and Zheng 2004; Steeneveld et al. 2008; Hu et al. 2010; Edwards et al. 2011; Svensson et al. 2011; Shin and Hong 2011; Gallée et al. 2015). They tended to focus on particular locations where diurnal cycles are pronounced or certain short time periods when intensive observations are available for comparison.

The performance of general circulation models (GCMs) in simulating the diurnal variability of the PBL parameters had received little attention until several years ago, while a number of GCM studies had been concerned with the variations at monthly, seasonal, and annual time scales, or the diurnal cycles of cloud cover and precipitation (cf. Lin et al. 2000). This was attributed at least in part to the lack of a database for the observed climatological diurnal cycles in different surface conditions across the globe. In recent years, however, a few studies have produced the climatologies of key PBL parameters based on in situ observations and/or modern reanalysis products, making it feasible to analyze the diurnal cycles of the near-surface variables simulated with GCMs (Liu and Liang 2010; Seidel et al. 2012; von Engeln and Teixeira 2013; Lindvall et al. 2013; Svensson and Lindvall 2015). For the PBL height, Liu and Liang (2010) constructed the climatologies over land, ocean, and ice surfaces from the fine-resolution ( 3 or 6 hourly) radiosonde sounding profiles collected in 14 field campaigns during 1987-2008 around the world. Seidel et al. (2012) analyzed the diurnal variations of the PBL height for 25 years (1981-2005) over Europe and continental United States, using the twice-daily radiosonde profiles and the European Centre for Medium-Range Weather Forecasts (ECMWF) interim reanalysis (ERA-Interim) at 3-h temporal resolution. Von Engeln and Teixeira (2013) generated a global PBL height climatology database from the ERA-Interim reanalysis for a 20-yr period (1990-2009) at 6 -h resolution, and validated their database with the radiosonde soundings covering both ocean and land conditions. Besides the PBL height, Lindvall et al. (2013) yielded observational climatology datasets for near-surface temperature and wind speed (at 2- and 10-m reference levels, respectively), and surface turbulent and radiative fluxes, by utilizing tower observations in a range of different climate zones. The datasets were used to evaluate the performance of the Community Earth System Model (CESM; Lindvall et al. 2013), and 16 models participating in phase 5 of the Coupled Model Intercomparison Project (CMIP5; Svensson and Lindvall 2015).

In this study, we document the performance of two Geophysical Fluid Dynamics Laboratory (GFDL) atmospheric general circulation models (AGCMs) in simulating the annual-mean and diurnal cycle climatologies of 2-m temperature, $10-\mathrm{m}$ wind speed, and PBL height. The only difference between them is in the PBL parameterization: one uses a prescribed K-profile parameterization (KPP) scheme with an entrainment parameterization (Lock et al. 2000), and the other employs a turbulence kinetic energy (TKE) PBL scheme (Mellor and Yamada 1974, 1982; Galperin et al. 1988). First the simulated climatologies are evaluated in a global perspective, compared with those in a reanalysis ensemble dataset. The reanalysis ensemble is generated from four reanalysis datasets: ECMWF twentieth-century reanalysis (ERA-20C), ERA-Interim from ECMWF, Climate Forecast System Reanalysis (CFSR) from National Centers for Environmental Prediction (NCEP), and Modern-Era Retrospective Analysis for Research and Applications (MERRA) from National Aeronautics and Space Administration (NASA) Goddard Space Flight Center (GSFC). In addition to the mean climatologies, this combined dataset provides information about their uncertainty range. In the second part, a detailed analysis of surface turbulent fluxes and vertical profiles is performed for the Sahara region, to concentrate on more specific roles of the turbulent mixing in dry PBLs in simulating the diurnal cycles. ERA-20C is used in this part, which reproduces the important features of the diurnal cycles in the region at the highest temporal and vertical resolutions among the four reanalysis datasets.

The rest of this paper is structured as follows. Section 2 describes two GFDL AGCMs and reanalysis datasets. In section 3, the simulated climatologies are evaluated through the comparison to the reanalysis ensemble. A detailed analysis of the surface turbulent fluxes and the vertical profiles is presented in section 4. Concluding remarks follow in the final section.

\section{Description of models and reanalysis datasets}

\section{a. Models}

Two GFDL models, based on the GFDL global atmosphere and land model (AM4.0/LM4.0; Zhao et al. 2018a,b), are used for this study. The two models are 
identical except for different PBL parameterizations and minor tuning for top-of-the -atmosphere (TOA) radiative balance. Both are based on the hydrostatic version of a finite-volume (FV) cubed-sphere dynamical core (Lin and Rood 1996, 1997; Lin 1997, 2004), with a horizontal resolution of about $100 \mathrm{~km}$. A hybrid sigma-pressure coordinate is configured with 33 interface levels from the surface to the model top at $1 \mathrm{hPa}$. This corresponds to 32 grid-center levels, and prognostic variables such as horizontal winds, temperature, and hydrometeors are computed at these grid-center levels. The GFDL AM4.0 includes a number of changes in atmospheric physics from the GFDL AM3 model (Donner et al. 2011). The main ones include a double-plume convection scheme (Zhao et al. 2016, 2018b) that is based on a modified University of Washington shallow cumulus scheme (Bretherton et al. 2004), and a new topographic drag parameterization (Garner 2005).

A typical PBL parameterization estimates the subgrid-scale (SGS) vertical transport of a prognostic variable $c\left(c=\bar{c}+c^{\prime} ; \bar{c}\right.$ is the resolved part at a given grid spacing, and $c^{\prime}$ is the corresponding unresolved perturbation). One can write

$$
\frac{\partial \bar{c}}{\partial t}=-\frac{\partial \overline{w^{\prime} c^{\prime}}}{\partial z} .
$$

The SGS transport of $c$ can be related to the vertical gradient of $\bar{c}$ using the eddy-diffusivity equation

$$
\overline{w^{\prime} c^{\prime}}=-K_{c} \frac{\partial \bar{c}}{\partial z},
$$

where $K_{c}$ is the vertical diffusivity for $c$. In both models, $K_{m}=K_{u}=K_{v}$ and $K_{t}=K_{q}$. The $m, u, v$, and $w$ refer to horizontal momentum, zonal wind, meridional wind, and vertical wind, respectively, and $t$ and $q$ refer to temperature and vapor mixing ratio, respectively.

The first model [referred to as K-profile parameterization (KPP)] uses a first-order $K$-profile scheme with an entrainment parameterization (Lock et al. 2000), and this is the standard PBL option in AM4.0 (Zhao et al. 2018a,b). Note that KPP does not have the countergradient heat transport term of Lock et al. (2000), which takes account of transports across a boundary layer by large eddies. In the case where there are either surfacedriven or cloud-top-driven mixed layers, the vertical diffusivity is calculated by combining the following four components: the prescribed $K$-profiles $K_{\text {prof }}$ and entrainment parameterizations $K_{\text {ent }}$ for surface-driven and cloud-top-driven mixed layers. In the following equations, the superscripts sfc and rad refer to surface-driven and radiatively driven, respectively:
$K_{c}(z)=K_{c, \text { prof }}^{\mathrm{sfc}}(z)+K_{c, \text { prof }}^{\mathrm{rad}}(z)+K_{c, \text { ent }}^{\mathrm{sfc}}(z)+K_{c, \text { ent }}^{\mathrm{rad}}(z)$.

The term $K_{c, \text { prof }}^{\mathrm{sfc}}$ is the diffusivity for surface-driven mixing by buoyancy and shear, and is added to $K_{c}$ only when the surface buoyant flux $b_{*}$ is upward:

$$
K_{c, \mathrm{prof}}^{\mathrm{sfc}}(z)=\left\{\begin{array}{cc}
\kappa\left(V_{\mathrm{sfc}}^{3}+V_{\text {shear }}^{3}\right)^{1 / 3} z\left(1-\frac{z}{z_{\mathrm{ml}}^{\mathrm{scc}}}\right)^{2}, & z<z_{\mathrm{ml}}^{\mathrm{scl}}, \\
0, & \text { elsewhere }
\end{array},\right.
$$

where $\kappa$ is the von Kármán constant $(\kappa=0.4)$, and $V_{\text {sfc }}$ and $V_{\text {shear }}$ are velocity scales representative of surface heating and surface friction, respectively. The term $z_{\mathrm{ml}}^{\mathrm{sfc}}$ is the surface-driven mixed-layer height.

The term $K_{c, \text { prof }}^{\mathrm{rad}}$ is the diffusivity for cloud-top-driven vertical mixing by longwave radiative cooling:

$$
K_{c, \mathrm{prof}}^{\mathrm{rad}}(z)=\left\{\begin{array}{cc}
0.85 \kappa V_{\mathrm{rad}} \frac{z^{\prime 2}}{d_{\mathrm{ml}}^{\mathrm{rad}}}\left(1-\frac{z^{\prime}}{d_{\mathrm{ml}}^{\mathrm{rad}}}\right)^{0.5}, & z_{b} \leq z<z_{\mathrm{ml}}^{\mathrm{rad}}, \\
0, & \text { elsewhere }
\end{array}\right.
$$

where $V_{\text {rad }}$ is a velocity scale representative of cloudtop radiative cooling, $d_{\mathrm{ml}}^{\mathrm{rad}} \equiv z_{\mathrm{ml}}^{\mathrm{rad}}-z_{b}$ is the depth of the radiatively driven mixed layer, and $z^{\prime} \equiv z-z_{b}$; terms $z_{\mathrm{ml}}^{\mathrm{rad}}$ and $z_{b}$ are the heights at the top and the base of the radiatively driven mixed layer, respectively.

For $K_{c, \text { ent }}^{\text {sfc }}$ and $K_{c, \text { ent }}^{\mathrm{rad}}$, the entrainment rates $w_{\mathrm{e}}$ are parameterized for computing the vertical mixing by entrainment at the top of the mixed layers (at $z_{\mathrm{ml}}^{\mathrm{scc}}$ and $z_{\mathrm{ml}}^{\mathrm{rad}}$, respectively) (Lock 1998; Lock et al. 2000):

(i) In the case when $z_{\mathrm{ml}}^{\mathrm{sfc}} \neq z_{\mathrm{ml}}^{\mathrm{rad}}$,

$$
\begin{aligned}
K_{c, \text { ent }}^{\mathrm{sfc}} & =\left\{\begin{array}{cc}
\left.w_{e, \mathrm{sfc}} \Delta z\right|_{z_{\mathrm{ml}}^{\mathrm{scc}}}, & z=z_{\mathrm{ml}}^{\mathrm{sfc}} \\
0, & \text { elsewhere }
\end{array}\right. \text { and } \\
w_{e, \mathrm{sfc}} & =\frac{\beta\left(V_{\mathrm{sfc}}^{3}+V_{\text {shear }}^{3}\right) / z_{m l}^{s f c}}{\left.\Delta b\right|_{z_{\mathrm{ml}}^{\mathrm{scc}}}+\left(V_{\mathrm{sfc}}^{3}+V_{\text {shear }}^{3}\right)^{2 / 3} / z_{\mathrm{ml}}^{\mathrm{scc}}},
\end{aligned}
$$

and

$$
\begin{aligned}
K_{c, \text { ent }}^{\mathrm{rad}} & =\left\{\begin{array}{cc}
\left.w_{e, \mathrm{rad}} \Delta z\right|_{z_{\mathrm{ml}}^{\mathrm{rad}}}, & z=z_{\mathrm{ml}}^{\mathrm{rad}} \\
0, & \text { elsewhere }
\end{array}\right. \text { and } \\
w_{e, \mathrm{rad}} & =\frac{\beta V_{\mathrm{rad}}^{3} / z_{\mathrm{ml}}^{\mathrm{rad}}}{\left.\Delta b\right|_{z_{\mathrm{ml}}^{\mathrm{rad}}}+V_{\mathrm{rad}}^{2} / z_{\mathrm{ml}}^{\mathrm{rad}}},
\end{aligned}
$$


where $w_{e, \text { sfc }}$ is the entrainment rate at $z_{\mathrm{ml}}^{\mathrm{sfc}}$ by surface heating and friction, $w_{e, \text { rad }}$ is the entrainment rate at $z_{\mathrm{ml}}^{\mathrm{rad}}$ by cloud-top radiative cooling, and $\left.\Delta z\right|_{z_{\mathrm{ml}}^{\mathrm{scc}}}$ and $\left.\Delta z\right|_{z_{\mathrm{ml}}^{\text {rad }}}$ are the vertical grid spacings at $z_{\mathrm{ml}}^{\text {sfc }}$ and $z_{\mathrm{ml}}^{\mathrm{rd}}$, respectively. The terms $\left.\Delta b\right|_{z_{\mathrm{ml}}^{\mathrm{scl}}}$ and $\left.\Delta b\right|_{z_{\mathrm{ml}}^{\text {rad }}}$ are the vertical gradients of buoyancy $b$ at $z_{\mathrm{ml}}^{\mathrm{sfc}}$ and $z_{\mathrm{ml}}^{\mathrm{rad}}\left(\left.\Delta b\right|_{z_{\mathrm{ml}}^{\mathrm{scc}}}=\left.g \Delta s_{l}\right|_{z_{\mathrm{ml}} \mathrm{sc}} /\left.s_{l}\right|_{z_{\mathrm{ml}}^{\mathrm{scc}}}\right.$ and $\left.\Delta b\right|_{z_{\mathrm{ml}}^{\text {rad }}}=\left.g \Delta s_{l}\right|_{z_{\mathrm{ml}}^{\text {rad }}} /\left.s_{l}\right|_{z_{\mathrm{ml}}^{\text {rad }}}$, where $s_{l}$ is liquid water virtual static energy). Variable $\beta$ is given a value 0.23 .

In the case when $z_{\mathrm{ml}}^{\mathrm{scc}}=z_{\mathrm{ml}}^{\mathrm{rad}}=z_{\mathrm{ml}}$,

$$
\begin{gathered}
K_{c, \text { ent }}=K_{c, \text { ent }}^{\mathrm{sfc}}+K_{c, \text { ent }}^{\mathrm{rad}}=\left\{\begin{array}{cc}
\left.w_{e} \Delta z\right|_{z_{\mathrm{ml}} l} & z=z_{\mathrm{ml}} \\
0, & \text { elsewhere }
\end{array}\right. \text { and } \\
w_{e}=\frac{\beta\left(V_{\mathrm{sfc}}^{3}+V_{\text {shear }}^{3}+V_{\mathrm{rad}}^{3}\right) / z_{\mathrm{ml}}}{\left.\Delta b\right|_{z_{\mathrm{ml}}}+\left(V_{\mathrm{sfc}}^{3}+V_{\text {shear }}^{3}+V_{\mathrm{rad}}^{3}\right)^{2 / 3} / z_{\mathrm{ml}}} .
\end{gathered}
$$

When there are neither surface-driven nor cloud-topdriven mixed layers, the diffusivity is parameterized as a function of the local Richardson number $K_{c, \mathrm{Ri}}$, according to Louis (1979):

$$
K_{c}(z)=K_{c, \mathrm{Ri}}(z)=l_{c}^{2} f_{c}\left|\frac{\partial U}{\partial z}\right|,
$$

where $l_{c}$ and $f_{c}$ are the mixing length and stability function for $c$, and $U$ is the horizontal wind speed.

The second model (referred to as TKE) uses a TKE PBL scheme based on the Mellor-Yamada 2.5-level model (Mellor and Yamada 1974, 1982). This scheme has a unified equation in computing the vertical diffusivity for various atmospheric conditions:

$$
K_{c}(z)=\sqrt{2 \bar{e}} l_{c}^{\mathrm{TKE}} S_{c},
$$

where $\bar{e}$ is the SGS TKE $\left(\bar{e} \equiv 0.5 \overline{u_{i}^{\prime} u_{i}^{\prime}}\right)$, and $l_{c}^{\mathrm{TKE}}$ and $S_{c}$ are the mixing length and stability function for $c$. The superscript TKE is used here for the mixing length to distinguish it from the length scale in the Louis scheme [Eq. (9)]. The scheme solves the SGS TKE from

$$
\frac{\partial \bar{e}}{\partial t}=\frac{g}{\overline{\theta_{v}}} \overline{w^{\prime} \theta^{\prime}}{ }_{v}-\overline{w^{\prime} u^{\prime}} \frac{\partial \bar{u}}{\partial z}-\overline{w^{\prime} v^{\prime}} \frac{\partial \bar{v}}{\partial z}-\frac{\partial \overline{w^{\prime} e^{\prime}}}{\partial z}-\varepsilon
$$

The first term on the right-hand side is buoyancy production, the second and third terms are shear production, the fourth term is the vertical transport of TKE, and the last term is dissipation. The SGS buoyancy term is computed as in Cuijpers and Duynkerke (1993):
TABLE 1. A summary of the global and annual-mean radiation budget $\left(\mathrm{W} \mathrm{m}^{-2}\right)$ at TOA in KPP and TKE schemes, with the reference data from CERES EBAF: the absorbed solar radiation (SWABS), the outgoing longwave radiation (OLR), and the net radiative balance (NET). The differences from CERES EBAF are presented in parentheses.

\begin{tabular}{lccc}
\hline & KPP & TKE & CERES EBAF \\
\hline SWABS & $239.13(-1.43)$ & $239.78(-0.78)$ & 240.56 \\
OLR & $237.77(-1.92)$ & $238.49(-1.20)$ & 239.69 \\
NET & $1.36(0.49)$ & $1.29(0.42)$ & 0.87 \\
\hline
\end{tabular}

$$
\frac{g}{\bar{\theta}_{v}} \overline{w^{\prime} \theta_{v}^{\prime}}=\frac{g}{\bar{\theta}_{v}}\left(A \overline{w^{\prime} \theta^{\prime}}+B \bar{\theta} \overline{w^{\prime} q_{t}^{\prime}}\right)
$$

with $A=1+0.61 \bar{q}_{t}$ and $B=0.61$ for unsaturated air, and

$$
\begin{gathered}
A=\frac{1-\bar{q}_{t}+1.61 \bar{q}_{s}\left(1+0.622 \frac{L}{R_{d} \bar{T}}\right)}{1+0.622 \frac{L}{R_{d} \bar{T}} \frac{L}{\bar{T} c_{p}} \bar{q}_{s}} \text { and } \\
B=\frac{L}{\bar{T} c_{p}} A-1,
\end{gathered}
$$

for saturated air. Variables $\bar{\theta}_{v}$ and $\bar{\theta}_{l}$ are the virtual potential temperature and the liquid water potential temperature, respectively, $\bar{q}_{t}$ is total water specific humidity, and $\bar{q}_{s}$ is the saturation specific humidity. Variable $L$ is the latent heat of vaporization, $c_{p}$ is the specific heat of dry air at constant pressure, and $R_{d}$ is the gas constant for dry air.

The length scale is computed as in Mellor and Yamada (1982):

$$
l_{c}^{\mathrm{TKE}}=\frac{\kappa z}{1+\kappa z / l_{0}}, \text { with } l_{0}=\alpha \frac{\int_{0}^{z_{\text {top }}} z q d z}{\int_{0}^{z_{\text {top }}} q d z} .
$$

The variable $l_{0}$ is the asymptotic value of $l_{c}^{\mathrm{TKE}} ; l_{c}^{\mathrm{TKE}} \sim \kappa z$ as $z \rightarrow 0$ and $l_{c}^{\mathrm{TKE}} \sim l_{0}$ as $z \rightarrow \infty$. The empirical constant $\alpha$ is set at 0.1 as in Mellor and Yamada (1974). The stability functions follow Galperin et al. (1988).

Changing the PBL scheme alters the global TOA energy balance from its value in KPP, and this could produce a change in the global-mean surface temperature (Hourdin et al. 2017). Therefore, the TOA radiative balance in TKE is tuned by altering the erosion constants in the large-scale cloud parameterization (Tiedtke 1993) and the ice-falling speeds in the cloud microphysics scheme (Rotstayn et al. 2000). The erosion constant when vertical diffusion is active is $8 \times 10^{-5} \mathrm{~s}^{-1}$ and the constant when convection is active is $6 \times 10^{-5} \mathrm{~s}^{-1}$ in TKE. In KPP, they are 4 and $3 \times 10^{-5} \mathrm{~s}^{-1}$, respectively. The ice-falling 
speeds follow Heymsfield and Donner (1990), multiplied by a factor of 1.5 in TKE and 1.0 in KPP, respectively. The main conclusions hold regardless of tuning. Table 1 summarizes the radiative budget at TOA in the models, with the reference from the Clouds and the Earth's Radiant Energy System (CERES) Energy Balanced and Filled (EBAF), Edition 2.8 (Ed2.8; Loeb et al. 2009). KPP and TKE have similar global-mean absorbed shortwave radiation and outgoing longwave radiation. The net radiation is around $1.3 \mathrm{~W} \mathrm{~m}^{-2}$ in both models.

The two models are driven by climatological sea surface temperature (SST) and sea ice boundary conditions based on phase 6 of the CMIP (CMIP6) dataset averaged over 1981-2014, and 10-yr model simulations are used in this study. The two-dimensional PBL parameters and surface turbulent fluxes are averaged and archived every $3 \mathrm{~h}$ (0000-0300, 0300-0600, . , 2100-0000 UTC), and the instantaneous three-dimensional variables are archived every $6 \mathrm{~h}$ (0000, 0600, 1200, and 1800 UTC).

\section{b. Reanalysis datasets}

To provide reference data for evaluating the models in a global perspective, a reanalysis ensemble for 2000-09 is generated from ERA-20C, ERA-Interim, CFSR, and MERRA. The reanalysis products have been used widely for various scientific applications as reference fields to overcome narrow spatial and temporal coverage of direct observations. Since the four reanalysis datasets have different temporal and spatial resolutions, we first calculate diurnal cycle climatologies for each reanalysis at its own resolution before interpolating the results to the coarsest temporal and spatial resolutions among the four datasets. The interpolated climatological fields on the same grid spacing are then averaged. The temporal resolution of the reanalysis ensemble is taken on a 6-h basis, that is, at $0000,0600,1200$, and 1800 UTC (as is the case for ERA-Interim and CFSR), and the horizontal resolution is approximately $125 \mathrm{~km}$ (as is the case for ERA20C). The standard deviation (STD) of the reanalysis ensemble is also computed from the differences between the climatologies of each reanalysis and the ensemble, and used to estimate the uncertainty of the reanalysis datasets. This is a major advantage of using the reanalysis ensemble over a single reanalysis product, given the deficiencies of the reanalysis products on various time scales and variables (Decker et al. 2012). Note that the four different reanalysis datasets were driven by different SST and ice boundary conditions from the GFDL models, while the difference among the reanalysis datasets is constrained by the data assimilation. The model bias from the reanalysis ensemble is likely larger than the STD of the reanalysis ensemble, except for data-sparse regions such as the Arctic (Lindsay et al. 2014) and the Tibetan
Plateau (Bao and Zhang 2013a). Some important details of each reanalysis dataset are provided below.

ERA-20C (Poli et al. 2016) covers the period 19002010 and is based on a version of the ECMWF Integrated Forecast System (IFS) (version cy38r1), which contains an AGCM and an incremental fourdimensional variational data assimilation (4D-VAR) analysis with 24-h analysis cycles. The atmospheric model in the IFS is configured with 91 vertical interface levels (90 grid-center levels) from the surface to $0.01 \mathrm{hPa}$. The horizontal resolution is approximately $125 \mathrm{~km}$, which corresponds to the spectral triangular truncation of T159. The temporal resolution of most two-dimensional and three-dimensional analysis variables is 3-hourly, while several surface parameters including 2-m temperature are available only every $6 \mathrm{~h}$. In the IFS version used for producing ERA-20C, the eddy-diffusivity mass-flux approach (a nonlocal scheme) is used for parameterizing turbulent transport in convective PBLs, while a local eddy-diffusivity approach based on local stability is used for stable PBLs and free atmosphere (ECMWF 2013). The PBL height is diagnosed as the lowest height where the bulk Richardson number between the surface and levels above reaches the critical Richardson number $\mathrm{Ri}_{\text {cr }}$ of 0.25 (Troen and Mahrt 1986).

ERA-Interim (Berrisford et al. 2011; Dee et al. 2011) starts from 1979 and continues in real time. The IFS version cy32r2 is used, and includes the 4D-VAR with 12-h analysis cycles. The atmospheric model component in the IFS version uses a horizontal resolution of approximately $80 \mathrm{~km}$ (T255 spectral truncation) and 60 vertical interface levels (59 grid-center levels) with the model top at $0.1 \mathrm{hPa}$. The temporal resolution of the ERA-Interim archive is 6-hourly. ERA-Interim and ERA-20C use the same PBL parameterization.

NCEP CFSR (Saha et al. 2010) covers the period from 1979 to the present. While others are based on atmospheric models driven by observed sea surface temperature and sea ice, CFSR uses a coupled global model, which consists of the NCEP Global Forecast System (GFS) and the GFDL Modular Ocean Model (MOM). The Gridpoint Statistical Interpolation (GSI) technique, a threedimensional variational data assimilation (3D-VAR) analysis, is used for atmospheric analysis with 6-h update cycles. The GFS model is configured with 65 vertical interface levels (64 grid-center levels) from the surface to approximately $0.266 \mathrm{hPa}$. The horizontal resolution is about $38 \mathrm{~km}$. The PBL height is computed according to the bulk Richardson number method with $\mathrm{Ri}_{\text {cr }}$ of 0.25 , which is consistent with the diagnostic method in ERA20C and ERA-Interim. 

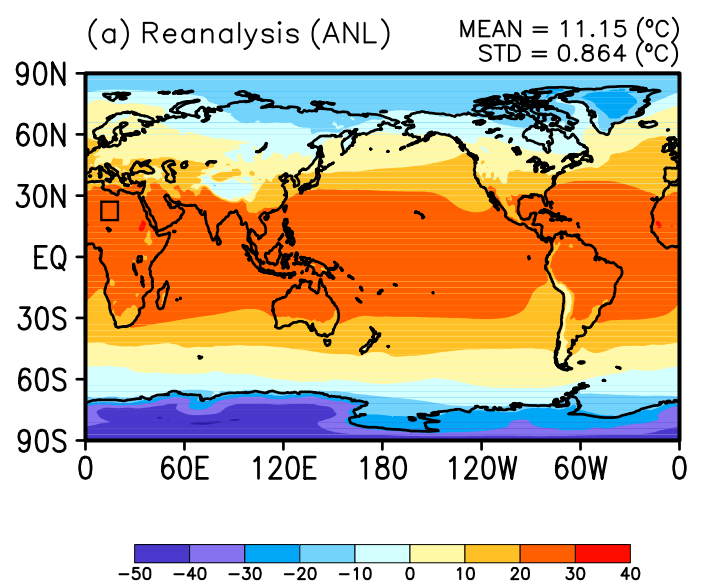

(c) TKE-ANL

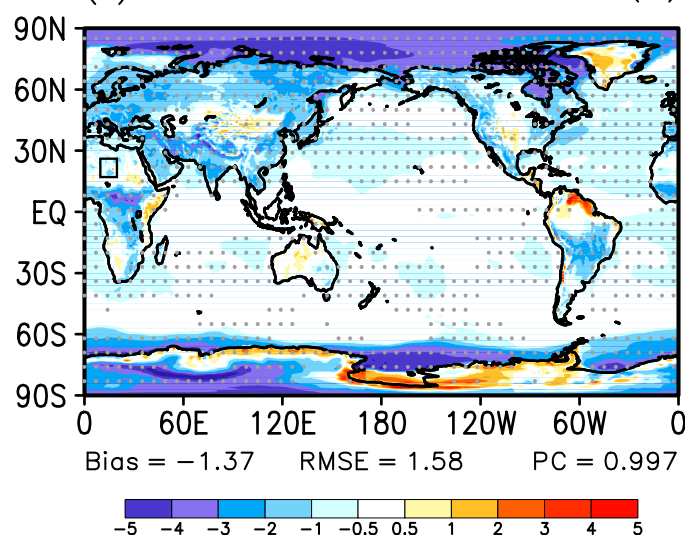

(b) KPP-ANL $\operatorname{KPP} M E A N=10.10\left({ }^{\circ} \mathrm{C}\right)$

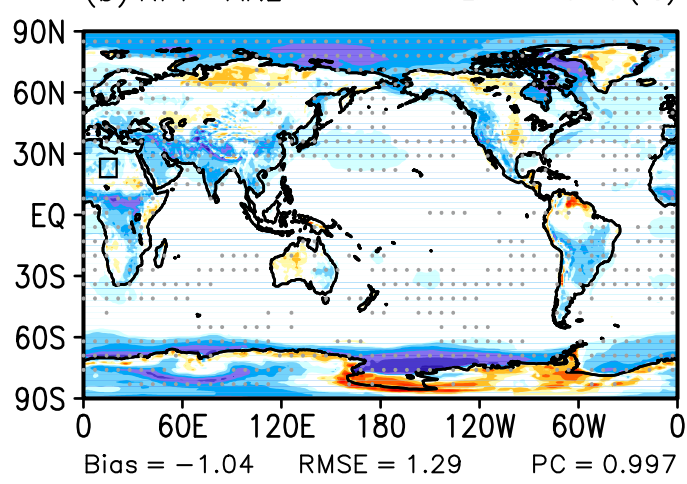

(d) TKE-KPP

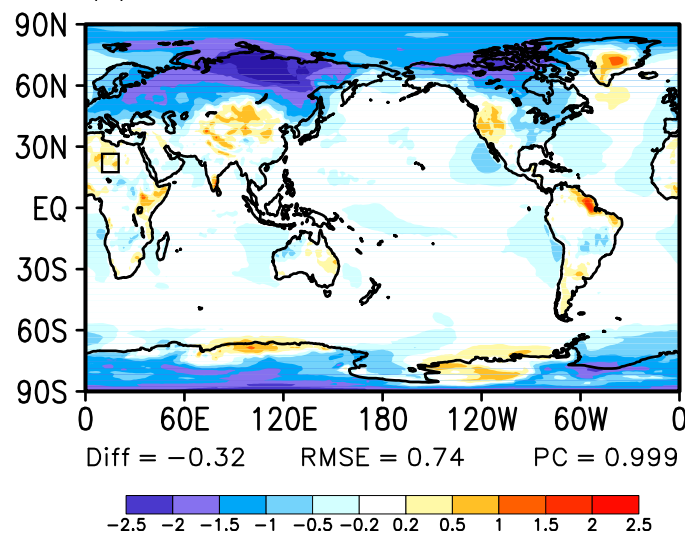

FIG. 1. (a) Annual-mean $T_{2}\left({ }^{\circ} \mathrm{C}\right)$ in ANL, and the difference between (b) KPP and ANL, (c) TKE and ANL, and (d) TKE and KPP. In (b), (c), the area where the model bias is larger than the STD of reanalysis datasets is indicated by gray dots (cf. section 2b). In (a)-(c), the global-mean temperatures for ANL, KPP, and TKE are presented at the top right; in (a), the global-mean STD is also presented. In (b)-(d), the global-mean bias, RMSE, and PC are presented at the bottom. To compute the statistics, a surface area-weighted averaging is used. The Sahara region $\left(18^{\circ}-28^{\circ} \mathrm{N}, 8^{\circ}-18^{\circ} \mathrm{E}\right)$ for the analysis in section 4 is marked by a rectangle in each panel.

NASA MERRA (Rienecker et al. 2011) is generated with the atmospheric model of the Goddard Earth Observing System (GEOS), version 5.2.0 (GEOS-5.2.0), and the GSI data assimilation system with 6-h update cycles. The MERRA product spans from 1979 to the present, with 72 vertical interface levels ( 71 grid-center levels) from the surface to $0.01 \mathrm{hPa}$ and $1 / 2^{\circ}$ latitude $\times 2 / 3^{\circ}$ longitude horizontal resolution. The two-dimensional parameters, such as $2-\mathrm{m}$ temperature and $10-\mathrm{m}$ wind components, are available every hour, and the threedimensional profiles are available every $3 \mathrm{~h}$. Unlike the other reanalysis datasets, the PBL height is diagnosed as the lowest model height where the vertical diffusivity falls below $2 \mathrm{~m}^{2} \mathrm{~s}^{-1}$ (McGrath-Spangler and Molod 2014). Despite the different definition of the PBL height, inclusion of MERRA in the reanalysis ensemble does not change the main findings of this study.

\section{Climatologies of PBL parameters}

In this section, the global annual-mean and diurnal cycle climatologies are presented for 2-m temperature $T_{2}, 10-\mathrm{m}$ wind speed $U_{10}$, and the PBL height (PBLH). Note that the models are integrated with the prescribed SSTs, therefore the statistics exclude the oceans. A surface area-weighted averaging is used to compute the statistics.

Figure 1 shows the 10-yr climatology of $T_{2}$ in the reanalysis ensemble (ANL) and the differences between the models and ANL. Both models reproduce the general patterns of $T_{2}$ in ANL [the pattern correlations (PCs) are 0.997] (Figs. 1a-c), but with the following biases. Widespread cold biases from 1 to $5 \mathrm{~K}$ are present over most continents, and the largest ones exceeding $3 \mathrm{~K}$ are found over the polar regions, namely, East Antarctica and the Arctic. The Northern Hemisphere middle 

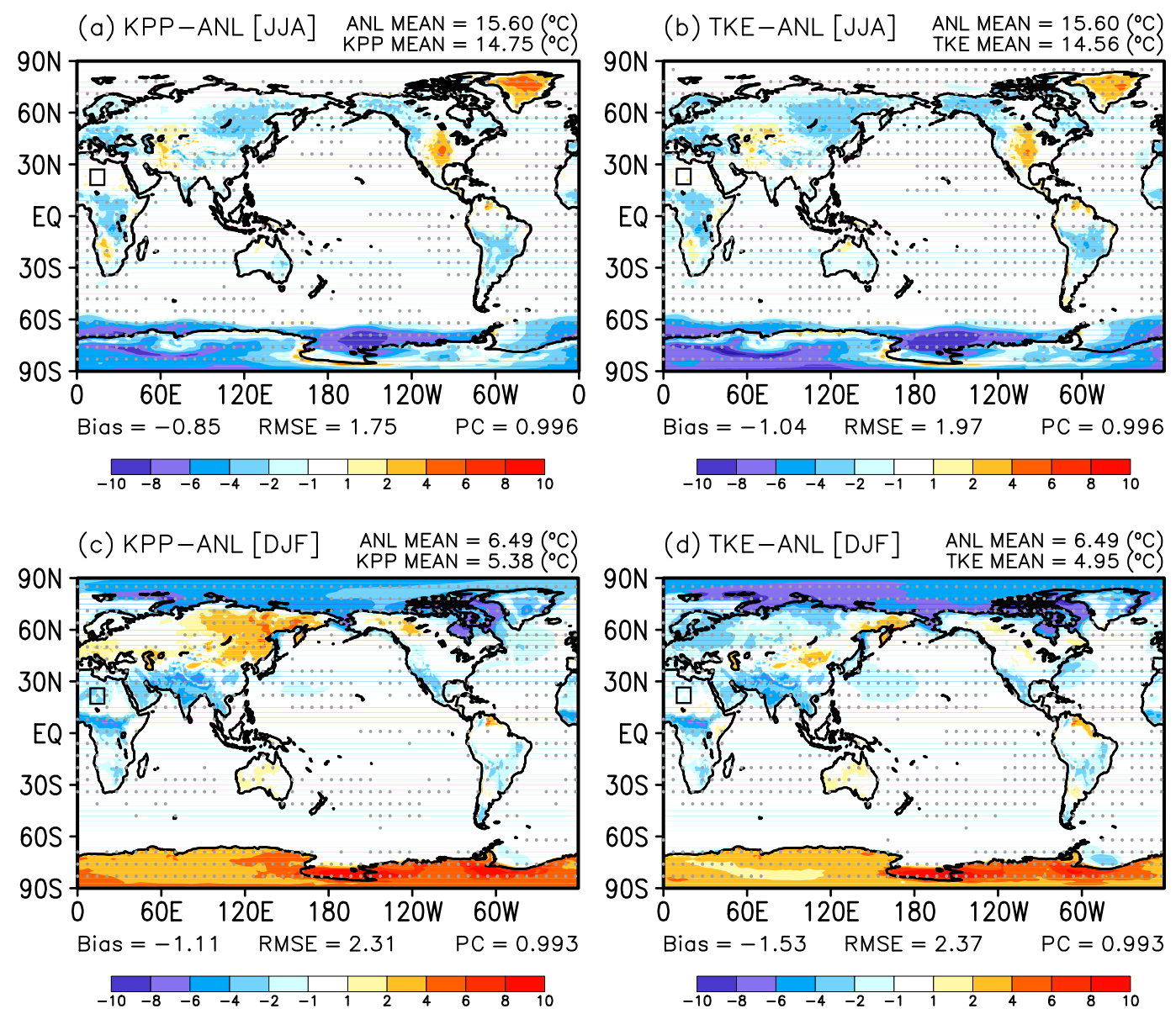

FIG. 2. Difference in $T_{2}\left({ }^{\circ} \mathrm{C}\right)$ between (a),(c) KPP and ANL, and (b),(d) TKE and ANL in (top) JJA and (bottom) DJF. The area where the model bias is larger than the STD of reanalysis datasets is indicated by gray dots. The globalmean temperatures are presented at the top right, and the global-mean bias, RMSE, and PC are presented at the bottom.

and high latitudes are appreciably colder in TKE than in KPP (Fig. 1d). The models slightly overestimate $T_{2}$ in most deserts and semiarid regions, but the biases are smaller than the STD of ANL. The dry regions are warmer in TKE than in KPP.

The models exhibit prominent seasonal variations of the temperature biases at the high latitudes (Fig. 2). In the Arctic Ocean, the cold biases seen in the annualmean climatologies are more severe in boreal winter than in boreal summer. The biases are larger in TKE than in KPP. The warm biases in Siberia and Alaska are distinct in boreal winter, opposite to the cold biases in the annual-mean climatologies. Zhao et al. (2018a) mentioned that some aspects of the biases are sensitive to the details of the land vegetation, for example, the masking of vegetation by snow, the change of static vegetation, and land use. The warm biases are smaller in TKE than in KPP. In Antarctica and Greenland, both KPP and TKE show the warm biases in local summer, in contrast to the cold biases in local winter.
Figure 3 displays the diurnal cycle amplitudes of $T_{2}$. The reanalysis ensemble shows a marked contrast between dry and humid regions. The diurnal cycles in humid regions, such as the eastern United States, and the Amazon and the Congo rain forests, are relatively weaker than in dry regions (Fig. 3a) because of the modulation by surface evaporative cooling. The global averages from KPP $(7.2 \mathrm{~K})$ and TKE $(7.3 \mathrm{~K})$ are within the uncertainty range of the reanalysis ensemble defined by the STD $(6.9 \pm 1.2 \mathrm{~K})$. Both KPP and TKE overestimate the diurnal amplitudes in the polar regions (Figs. $3 b$ and $3 c$, respectively), where the biggest cold biases are found (cf. Figs. 1 and 3). The models tend to underestimate the diurnal amplitudes at the low and middle latitudes. The reanalysis uncertainties over the mountainous regions and/or deserts also tend to be large (Bao and Zhang 2013a), and the STD is bigger than the model bias in some of the regions. Between the two models, TKE performs better than KPP in capturing the strong cycles over the dry regions (e.g., the Sahara, 

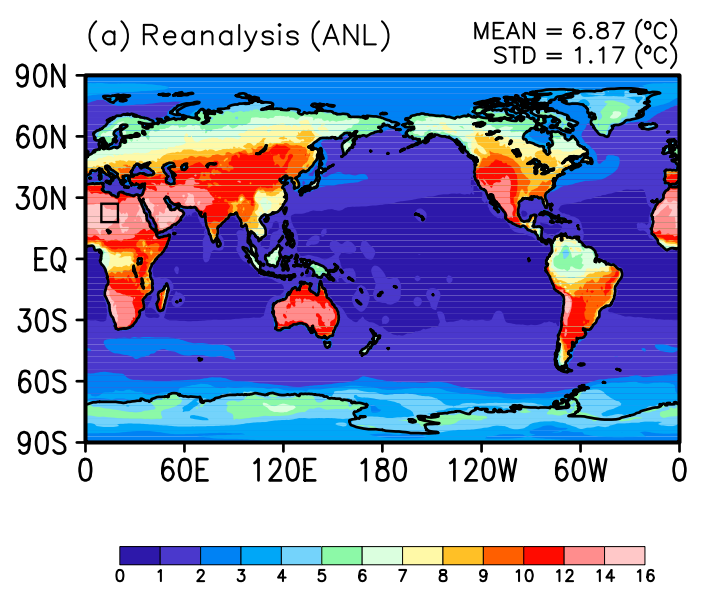

(c) TKE-ANL

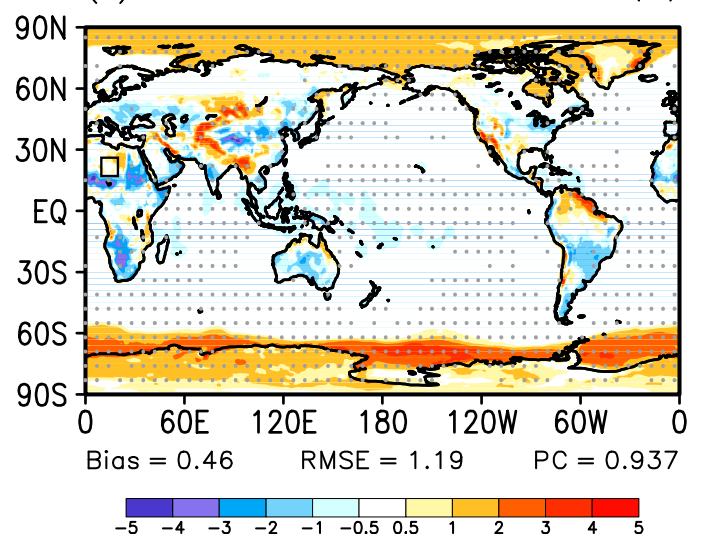

(b) KPP-ANL $\operatorname{KPP} M$ MEAN $=7.21\left({ }^{\circ} \mathrm{C}\right)$

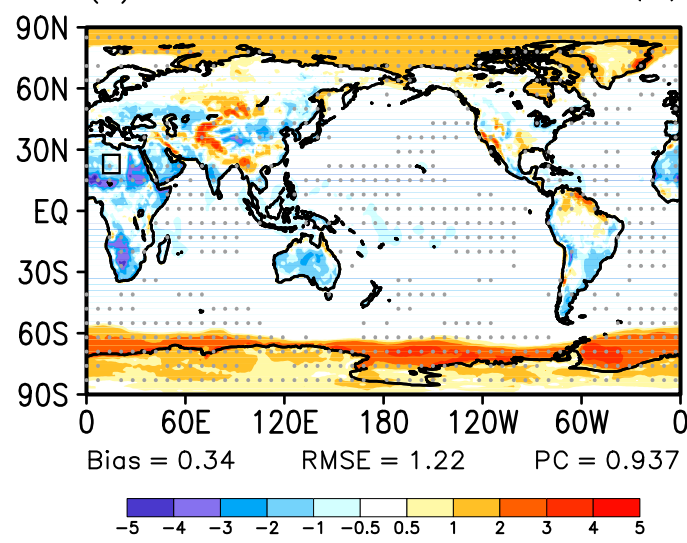

(d) TKE-KPP

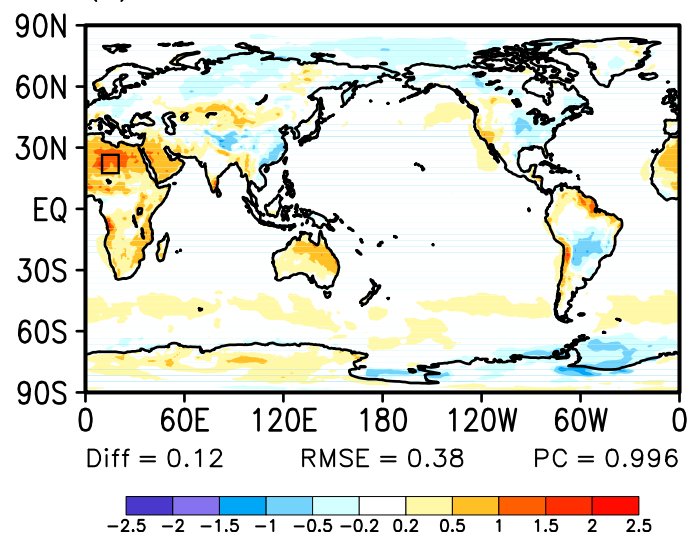

FIG. 3. As in Fig. 1, but for diurnal cycle amplitude of $T_{2}\left({ }^{\circ} \mathrm{C}\right)$.

southern Africa, and Australia) (Fig. 3d). The diurnal phases, the hours of maximum $T_{2}$, are well captured by the models (not shown).

The 10-yr climatologies of $U_{10}$ are compared in Fig. 4. Both models exhibit systematic negative biases over land and positive biases over the oceans (Figs. $4 \mathrm{~b}, \mathrm{c}$ ), and the biases are larger than the STD of ANL. The two models differ by less than $0.5 \mathrm{~m} \mathrm{~s}^{-1}$ (Fig. 4d). These features in the simulated $U_{10}$ are found throughout all seasons (not shown). The bias patterns of the diurnal amplitudes are similar to those of $U_{10}$ (Fig. 5); the amplitudes are underestimated over land, and there is not much difference between the models. Unlike $T_{2}$, the diurnal phases of $U_{10}$ in the models do not coincide with those in the reanalysis (not shown). The hours of the maximum daily winds are between 0900 and 1500 LT in the reanalysis, while they are more divergent in the models. The phase errors will be further discussed in section 4 .

Figure 6 presents the PBLH climatologies. As described in section $2 b$, the reanalysis datasets, except for MERRA, provide the PBLHs diagnosed using the bulk
Richardson number method. The same method is used to compute the PBLH in the GFDL models (Seidel et al. 2012). Note that the inclusion of MERRA does not change the main findings below, despite the difference in methodologies. In ANL (Fig. 6a), the highest PBLHs over land are found in the subtropical dry regions. The lowest values are reached in Antarctica and Greenland, with the annual-mean heights lower than $200 \mathrm{~m}$. These gross features are captured by the models, but not without some common biases (Figs. 6b,c). The models tend to underestimate (overestimate) the PBLHs in the cold-bias regions (in the warm-bias regions) (cf. Figs. 1b,c and $6 \mathrm{~b}, \mathrm{c}$ ), except for the East Antarctica plateau. The correlations between the PBLH and temperature biases are to some extent expected. As dictated by the PBLH diagnostic method used in this study, the PBLHs are positively correlated with the near-surface temperatures. The amplitudes of the diurnal cycles of the PBLH are presented in Fig. 7. ANL shows the intense diurnal cycles with the amplitudes larger than $2 \mathrm{~km}$ in the low- and midlatitude dry regions over land. Both models underestimate the diurnal 
(a) Reanalysis (ANL) MEAN $=4.30\left(\mathrm{~m} \mathrm{~s}^{-1}\right)$
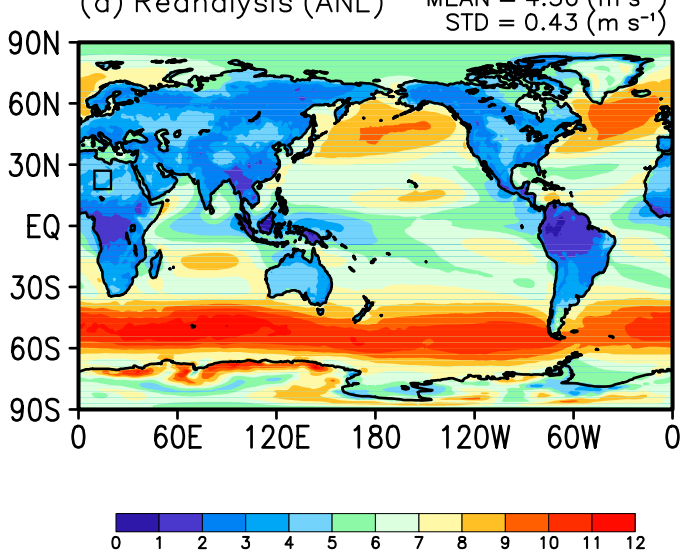

(c) TKE-ANL

TKE MEAN $=3.49\left(\mathrm{~m} \mathrm{~s}^{-1}\right)$

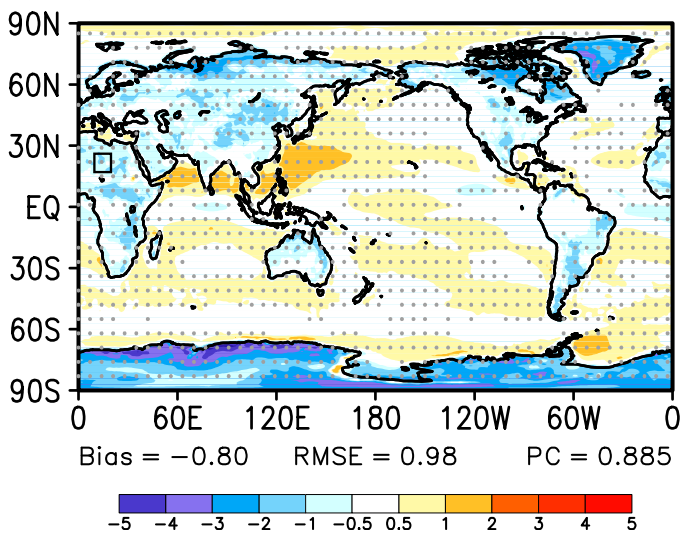

(b) KPP-ANL $\operatorname{KPP}$ MEAN $=3.50\left(\mathrm{~m} \mathrm{~s}^{-1}\right)$
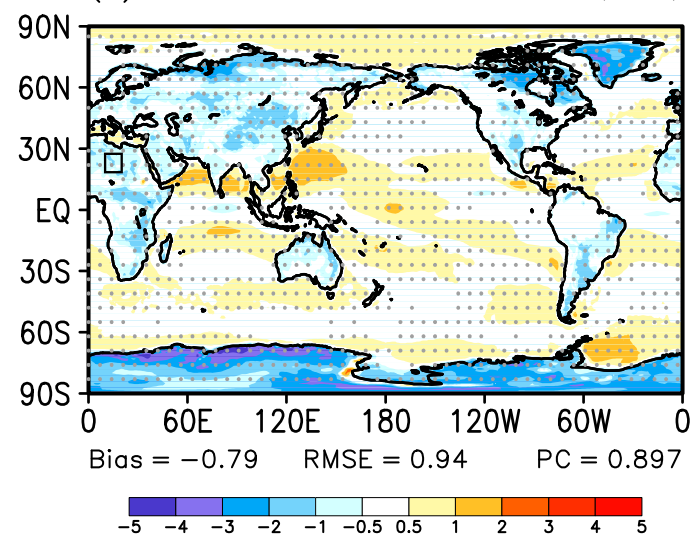

(d) TKE-KPP

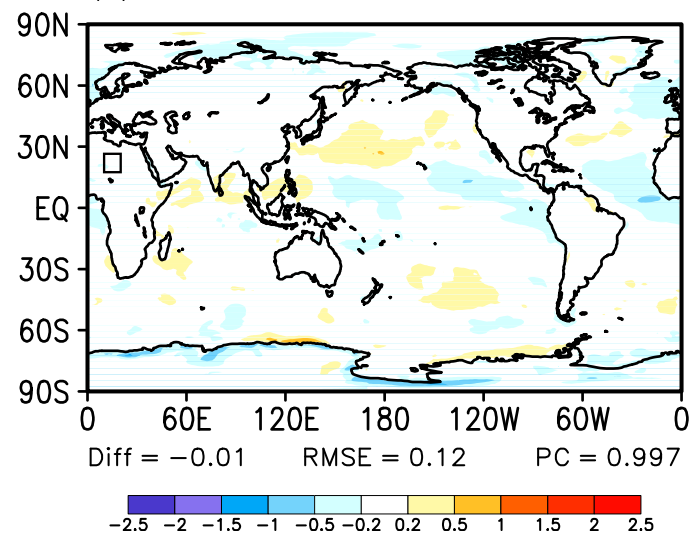

FIG. 4. As in Fig. 1, but for $U_{10}\left(\mathrm{~m} \mathrm{~s}^{-1}\right)$.

amplitudes over land (Figs. 7b,c). The amplitudes are larger in TKE than in KPP (Fig. 7d), though they are both smaller than in ANL.

In summary, the two AGCMs reproduce the overall patterns of $T_{2}, U_{10}$, and PBLH, while the following systematic errors are found. For $T_{2}$, the models exhibit the widespread cold biases in the high latitudes on an annual basis, and the biases are more severe in TKE than in KPP. The prominent seasonal variations of the temperature biases are seen in Siberia and Alaska, with the warm biases in boreal winter. The warm biases are alleviated in TKE. The diurnal amplitudes of $T_{2}$ are underestimated in the low- and midlatitude dry regions. Between the models, TKE simulates the amplitudes better than KPP. For $U_{10}$, common negative biases are found in the models, both in the daily means and in the diurnal variations. The bias patterns of the PBLH climatologies and the differences between the models are well correlated with those of $T_{2}$ over land. In the following section, a detailed analysis is performed for the biases in the dry region over land, to identify the role of turbulent mixing in dry PBLs in simulating the PBL parameters and their diurnal cycles.

\section{Role of the turbulent mixing}

The two models are evaluated in more detail, including the surface turbulent fluxes and the vertical structures in the PBL, to understand the role of the turbulent mixing in the difference between the models and/or systematic biases. A detailed analysis is performed for the Sahara region $\left(18^{\circ}-28^{\circ} \mathrm{N}, 8^{\circ}-18^{\circ} \mathrm{E}\right)$, where the differences in $T_{2}$ between the models and the common biases in $U_{10}$ are pronounced. This region is less likely to be influenced by precipitation and more suitable for discussing the role of the dry boundary layer mixing processes. ERA-20C is used for the evaluation, since it captures the important features of the observed diurnal cycles in the region well, at the highest temporal and vertical resolutions. For instance, in situ observations in the Sahara region show the increase of $U_{10}$ during the morning transition followed by the daytime 

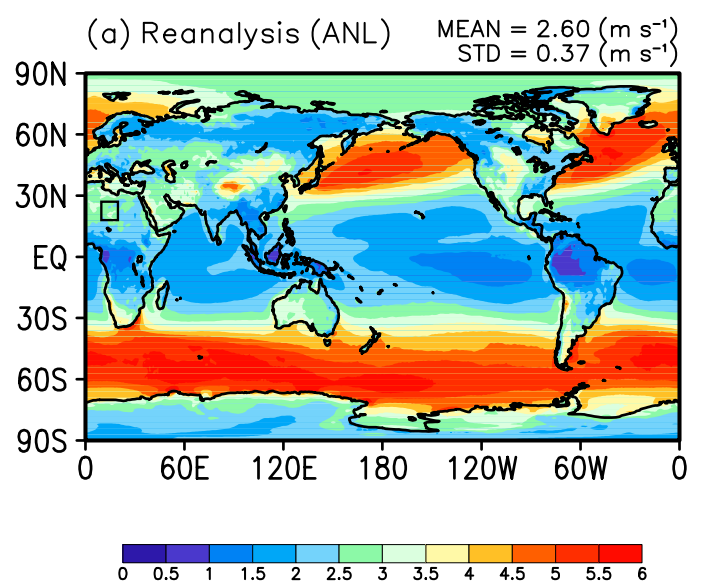

(c) TKE-ANL TKE MEAN $=2.16\left(\mathrm{~m} \mathrm{~s}^{-1}\right)$

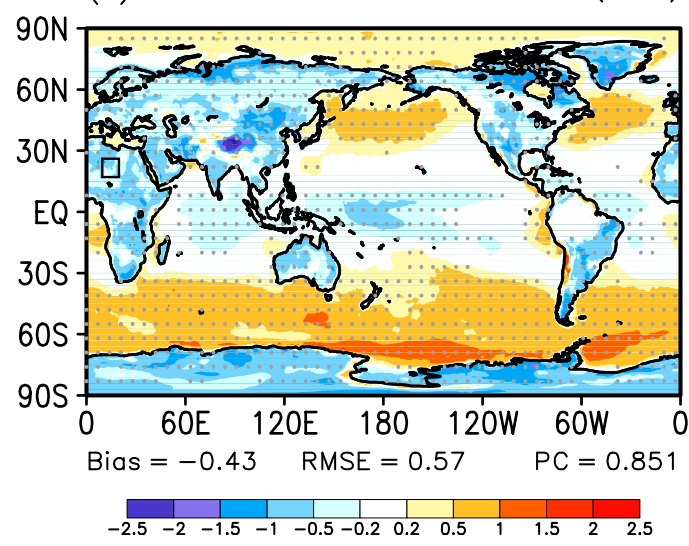

(b) KPP-ANL KPP MEAN $=2.22\left(\mathrm{~m} \mathrm{~s}^{-1}\right)$

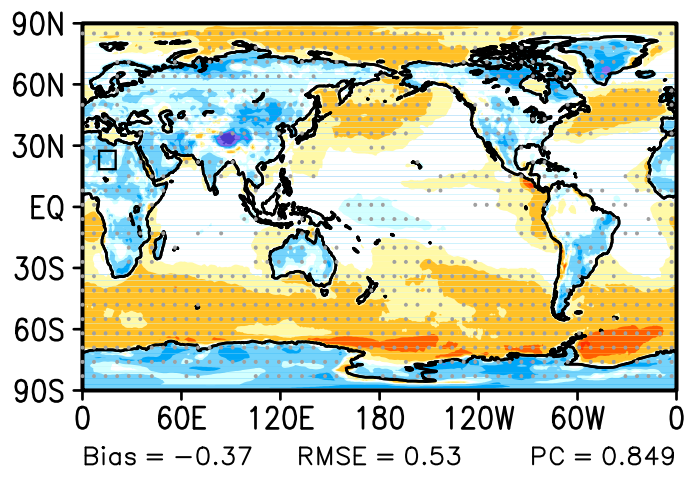

(d) TKE-KPP

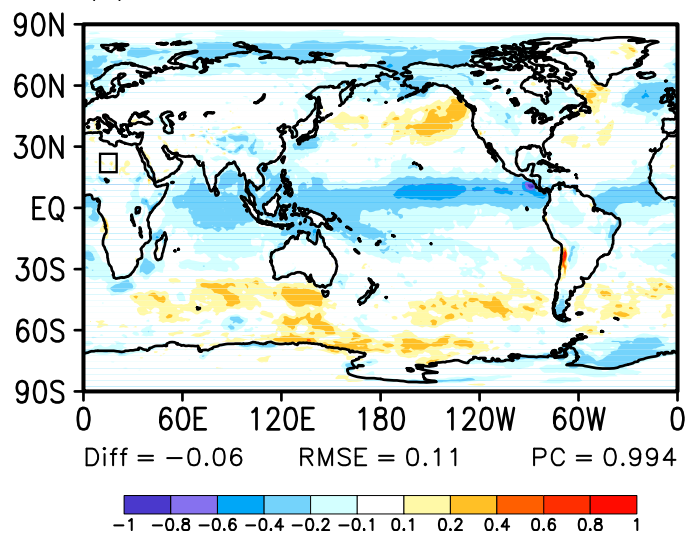

FIG. 5. As in Fig. 3, but for diurnal amplitude of $U_{10}\left(\mathrm{~m} \mathrm{~s}^{-1}\right)$.

peak of $U_{10}$ (Marsham et al. 2013), and the transition and peak in ERA-20C is the most similar to those observed among the four reanalysis datasets used in section 3. For simplicity, the abbreviation ERA is used in place of ERA-20C hereinafter. Note that using the different datasets (ANL and ERA) could cause an inconsistency in the biases, but the key findings on the role of the vertical mixing hold regardless.

Figure 8 shows the 10 -yr-averaged diurnal cycles in the Sahara region for $T_{2}$ and surface sensible heat (SH) flux. The daily means of the parameters are presented in the top left of each panel of Fig. 8. For the time series of $T_{2}$, the daily means are subtracted for an easier comparison of the diurnal variations. The mean temperatures are slightly warmer in the models than in ERA (Fig. 8a). This is inconsistent with Fig. 1, but the biases in the region are smaller than the STD of ANL. The diurnal amplitudes are larger in the models, but the different temporal resolutions between the models ( 3 hourly) and ERA ( 6 hourly) may contribute to this. The two models behave similarly during the morning and evening transitions, while the maximum (minimum) temperature is $0.8^{\circ} \mathrm{C}$ warmer $\left(0.4^{\circ} \mathrm{C}\right.$ colder $)$ in TKE than in KPP. This is consistent with the larger diurnal amplitudes and the warmer mean temperatures in TKE, shown in Figs. 1d and 3d. Given the similar surface heat fluxes (Fig. 8b) but the different PBLHs (Figs. 6d and 7d) between the models, the turbulent mixing in the PBL may contribute to the different diurnal variations.

The climatological profiles of potential temperature, diffusivity for heat $K_{t}$, and heating rate due to vertical diffusion are compared in Fig. 9. Figure 9a shows the potential temperature profiles at $0700,1300,1900$, and 0100 LT (i.e., 0600, 1200, 1800, and 0000 UTC). The temperature of the entire PBL is warmer in TKE than that in KPP, which is attributed to the weaker cold advection in TKE (not shown). While the PBL is warmer in TKE all day, the temperature difference between the two models undergoes a diurnal variation (the maximum difference at $1300 \mathrm{LT}$ and the minimum difference at 0700 LT). This diurnal variation will be explained by the differences in vertical mixing between the models. 


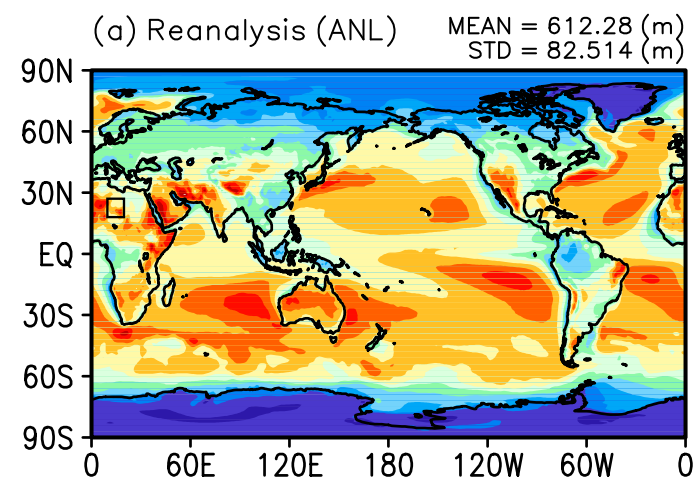

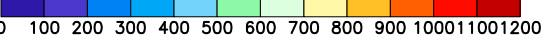

(c) TKE-ANL

TKE MEAN $=579.69(\mathrm{~m})$

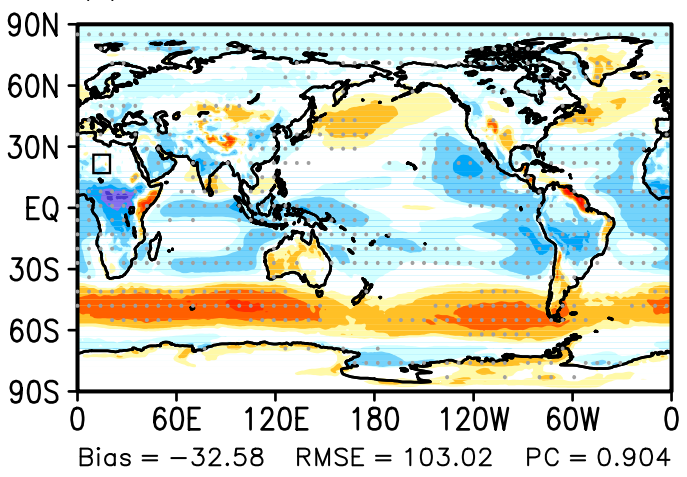

(b) $\mathrm{KPP}-\mathrm{ANL}$ $\operatorname{KPP} M E A N=580.58(m)$

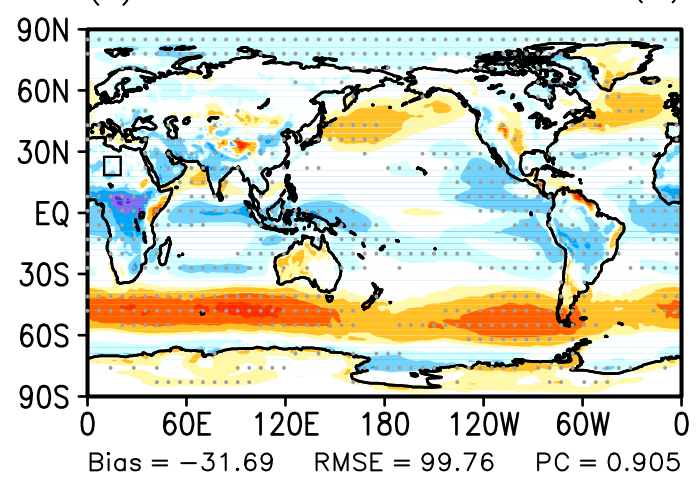

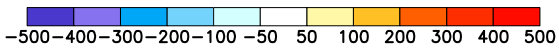

(d) TKE $-K P P$

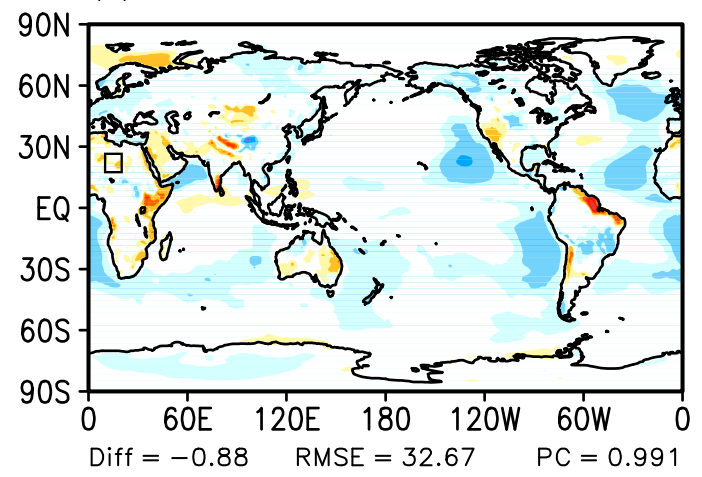

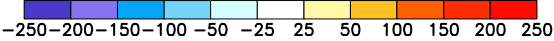

FIG. 6. As in Fig. 1, but for PBLH (m).

ERA shows a sharp gradient near the surface at 0700 LT, which is missing in the models. The sharp gradient in ERA may be attributed to the data assimilation, as well as the higher vertical resolution than that in the models. The surface heat flux starts to increase at around $0600 \mathrm{LT}$, and the well-mixed layer is found in ERA at $1300 \mathrm{LT}$ (Figs. 8b and 9a). In stark contrast, the vertical profiles in the two models are unstably stratified. This is a known limitation of eddy-diffusivity parameterization schemes without countergradient or mass-flux terms in representing the convective boundary layers [after Holtslag and Boville (1993) and Hong and Pan (1996)]. The temperature profiles in the atmospheric models with the eddy-diffusivity PBL schemes remain superadiabatic to transport the surface heat upward; the eddy-diffusivity equation [i.e., Eq. (2)] cannot compute the upward heat transport when the profiles are adiabatic or subadiabatic. Between the models, TKE simulates a warmer and more unstably stratified PBL at 1300 LT than KPP, despite the similar surface heat fluxes (cf. Fig. 8b). The weaker vertical mixing in TKE resulting from the smaller diffusivity accounts for the more unstable profile; the less efficient heat transport in TKE results in more (less) warming near the surface (in the upper PBL) than in KPP (Figs. 9b,c). After sunset, a nocturnal stable boundary layer starts to form at around 1900 LT in ERA by radiative cooling. The models also show the cooling in the PBL. The PBL cools more quickly in TKE than in KPP probably because of the weaker turbulent mixing in TKE (Figs. 9b, c), and the near-surface temperature difference between the models decreases from 1300 to 1900 LT. The stronger cooling in TKE continues during nighttime (0100 LT), and the near-surface temperature difference between the models continues to decrease. The analysis for $T_{2}$ shows how the vertical mixing by the PBL schemes has influence on the simulated diurnal amplitudes in this dry region.

The climatological diurnal variations of $U_{10}$ are presented in Fig. 10. From in situ observations in the central Sahara, Marsham et al. (2013) revealed that $U_{10}$ increases during the morning transition; the PBL deepens 
(a) Reanalysis (ANL) MEAN $=1088.12(\mathrm{~m})$

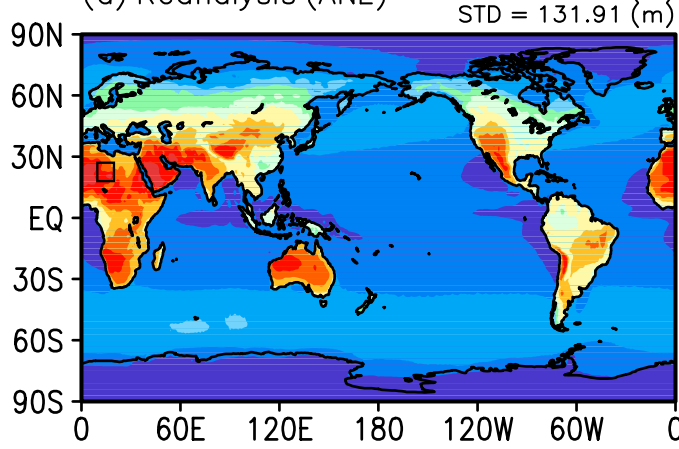

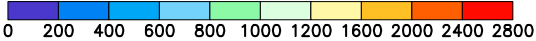

(c) TKE-ANL

TKE MEAN $=995.71(\mathrm{~m})$

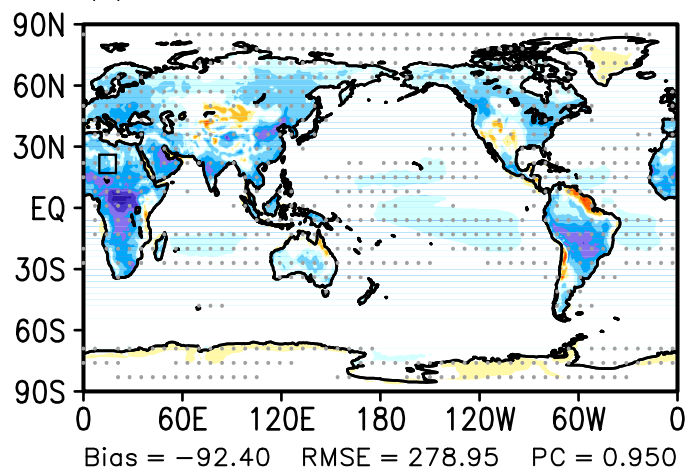

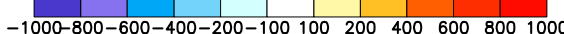

(b) KPP-ANL KPP MEAN $=975.68(\mathrm{~m})$

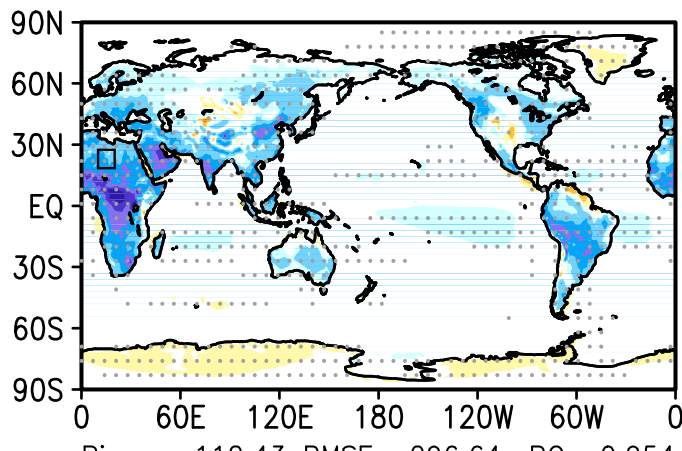

Bias $=-112.43$ RMSE $=296.64 \quad P C=0.954$

$-1000-800-600-400-200-100100 \quad 200 \quad 400 \quad 600 \quad 8001000$

(d) TKE -KPP

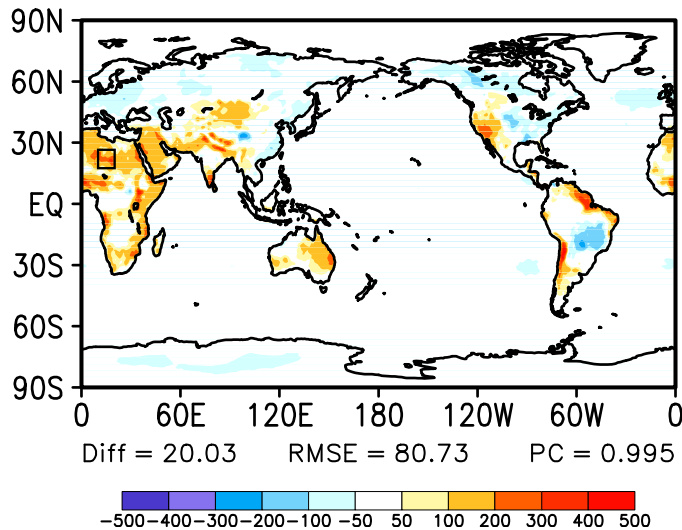

FIG. 7. As in Fig. 3, but for diurnal amplitude of PBLH (m).

after sunrise, transporting momentum from the nocturnal low-level jet (LLJ) to the surface. ERA captures this well. On the other hand, $U_{10}$ decreases during the morning transition in the models. This is consistent with the systematic underestimation of the near-surface winds and the diurnal amplitudes in the models (Figs. 4 and 5), implying that the downward momentum transport in the convective PBLs is underestimated in
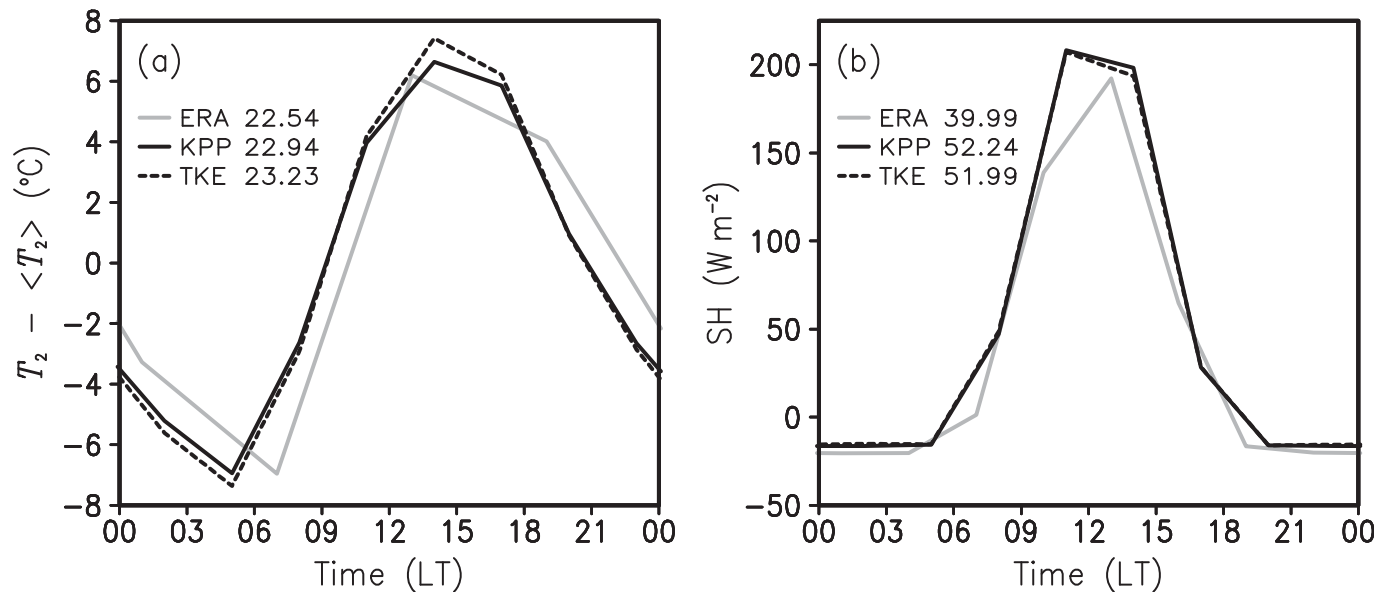

FIG. 8. Diurnal cycles of (a) $T_{2}\left({ }^{\circ} \mathrm{C}\right)$ and (b) surface SH flux $\left(\mathrm{W} \mathrm{m}^{-2}\right)$ in the Sahara region $\left(18^{\circ}-28^{\circ} \mathrm{N}, 8^{\circ}-18^{\circ} \mathrm{E}\right)$ : ERA (solid gray), KPP (solid black), and TKE (dotted black). The Sahara region is marked by rectangles in Figs. 1-7. The daily means for the parameters are shown in the top left of the corresponding panels. In (a), the daily means of $T_{2}$ are subtracted from the diurnal cycles. 
(a) Potential temperature (K)

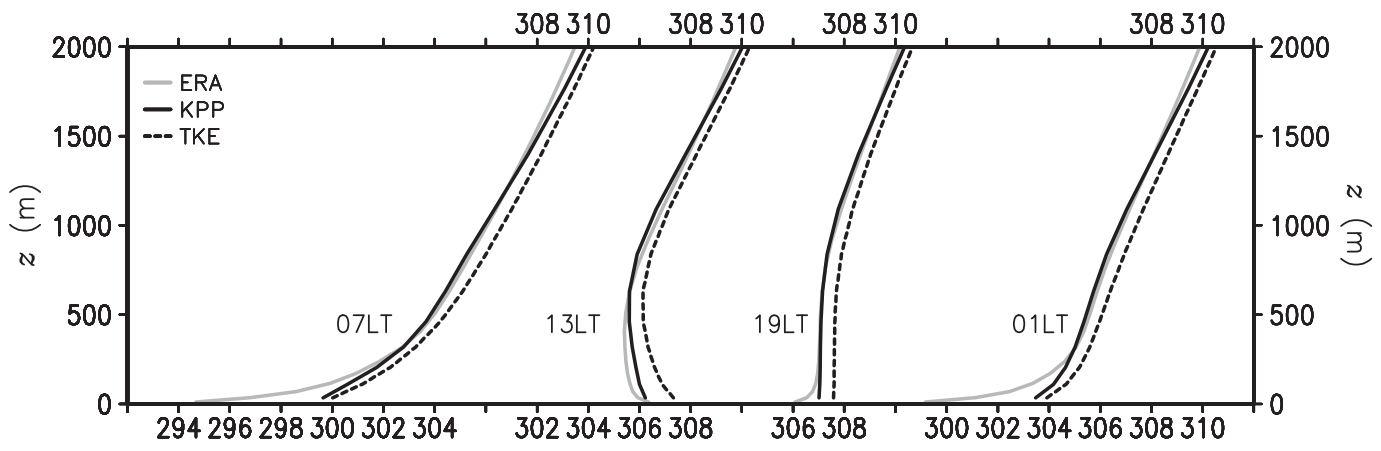

(b) Vertical diffusivity for heat $\left(K_{\mathrm{t}}\right)\left(\mathrm{m}^{2} \mathrm{~s}^{-1}\right)$

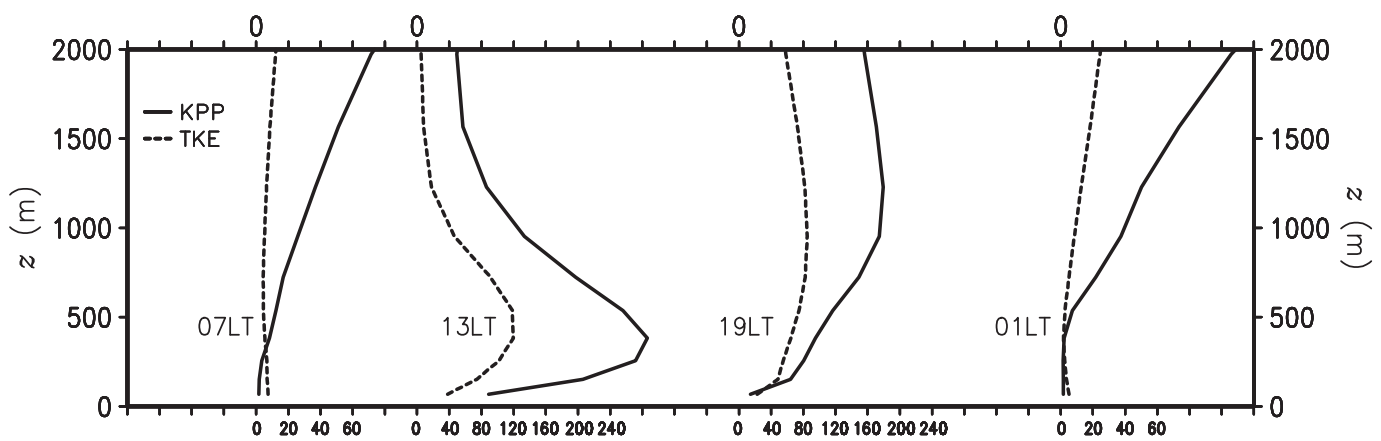

(c) Heating rate due to vertical diffusion $\left(10^{-4} \mathrm{~K} \mathrm{~s}^{-1}\right)$

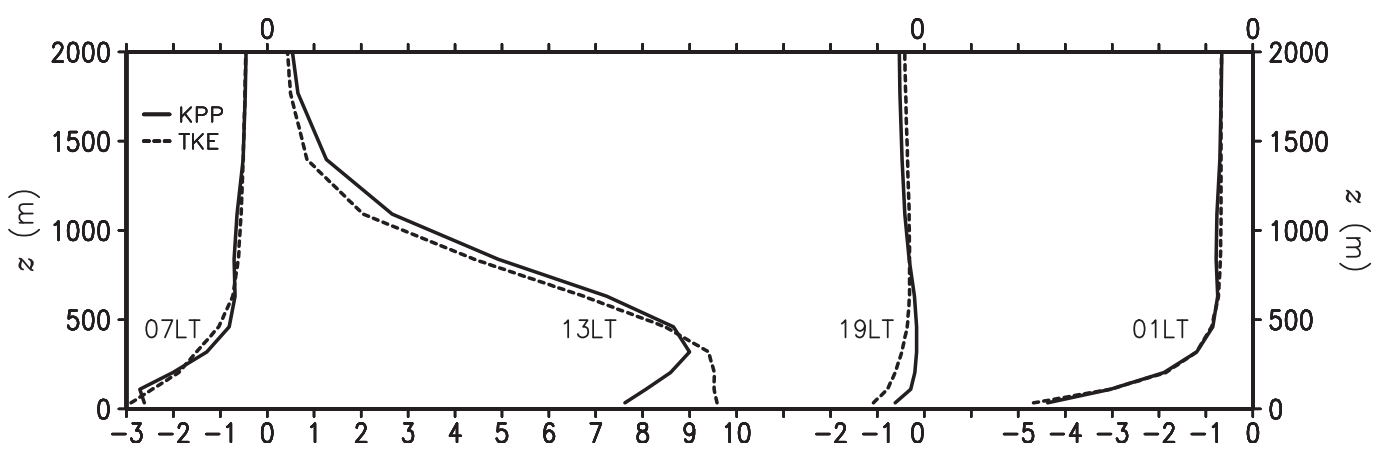

FIG. 9. Vertical profiles of (a) potential temperature (K), (b) $K_{t}\left(\mathrm{~m}^{2} \mathrm{~s}^{-1}\right)$, and (c) heating rate due to vertical diffusion $\left(10^{-4} \mathrm{~K} \mathrm{~s}^{-1}\right)$ at $0700,1300,1900$, and $0100 \mathrm{LT}$ (i.e., 0600, 1200, 1800, and $0000 \mathrm{UTC}$ ) in the Sahara region for ERA (solid gray), KPP (solid black), and TKE (dotted black).

the models. To demonstrate this, the vertical profiles of the horizontal wind speed are analyzed in Fig. 11. ERA shows the nocturnal LLJ below $500 \mathrm{~m}$ at 0100 and 0700 LT, and the two models also produce the LLJs. The simulated ones are $0.5-1 \mathrm{~m} \mathrm{~s}^{-1}$ stronger than that in ERA at 0100 LT, and the differences from ERA increase up to $1-2 \mathrm{~ms}^{-1}$ at $0700 \mathrm{LT}$. Between the two models, KPP simulates stronger LLJ. Once the LLJs are generated in the models, their magnitudes do not decrease until sunrise because of the small diffusivities (cf. Fig. 9b). Even though the LLJs are stronger in the models than in ERA, the simulated 10-m winds do not increase after sunrise, indicating that the models do not efficiently transport the momentum from the LLJs to the surface because of a lack of nonlocal turbulent mixing. The winds remain large in the upper PBL at $1300 \mathrm{LT}$, and the well-mixed profile in the reanalysis is not found in the simulations. This explains why the simulated diurnal cycles of $U_{10}$ are out of phase with those in the reanalysis and those observed. The systematic problem in $U_{10}$ was also reported by Holtslag et al. (2013); most operational weather and climate 


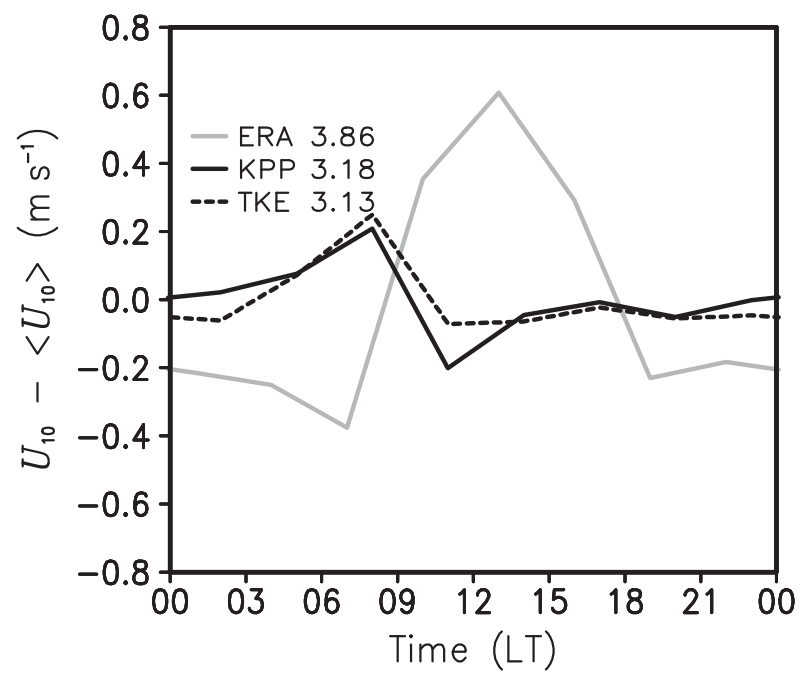

FIG. 10. As in Fig. 8a, but for $U_{10}\left(\mathrm{~m} \mathrm{~s}^{-1}\right)$.

models, including CMIP5 climate models, overestimate the near-surface winds during nighttime, while they do not increase enough after the morning transition (Svensson et al. 2011; Holtslag et al. 2013; Svensson and Lindvall 2015).

\section{Summary and discussion}

This study assessed the skill of two GFDL AGCMs, which differ only in PBL schemes, in simulating the climatologies of the PBL parameters: 2-m temperature, 10-m wind speed, and the PBL height. We focused on the diurnal variations of the near-surface variables, which have received less attention than the variations at longer time scales. The simulated results were evaluated against the reanalysis ensemble generated by integrating ERA-20C, ERA-Interim, NCEP CFSR, and NASA MERRA. It was found that the overall patterns of the near-surface parameters in the models agree well with those in the reanalysis, but several systematic biases were identified. The biases are listed as follows.

- The models underestimate $T_{2}$ over most continents and the Arctic on an annual basis regardless of the PBL parameterization. These cold biases are larger in the model that uses the TKE scheme. On the other hand, large warm biases are found in Siberia and Alaska in boreal winter in the model with the KPP scheme. They are significantly reduced with the TKE scheme, but the model exhibits cold biases instead.

- The models underestimate the diurnal amplitudes in the arid and semiarid regions. The diurnal amplitudes are better captured with the TKE scheme.

- The models underestimate both the daily means and the diurnal amplitudes of $U_{10}$, and the differences between the models are relatively small compared to the magnitudes of the biases common to the models.

- The bias patterns of the PBLHs in the low latitudes are in agreement with those of $T_{2}$; the models underestimate the PBLHs, except for the dry regions. The models tend to overestimate the PBLHs in the high latitudes.

The detailed analysis of the surface turbulent fluxes and the vertical profiles was performed for the Sahara region and helped identify the role of PBL parameterization schemes in the PBL simulation in the dry regions. The key findings are as below.

- The daytime PBLs remain unstable in the models, while the well-mixed profiles are found in the reanalysis. This means that the simulated PBLs would be warmer near the surfaces and colder in the upper PBL than the reanalysis, if the PBL-mean temperatures are the same between the models and the reanalysis.

- The vertical heat transport in the convective PBLs is weaker in the TKE PBL scheme than in the KPP scheme, leaving more heat in the lower PBL and

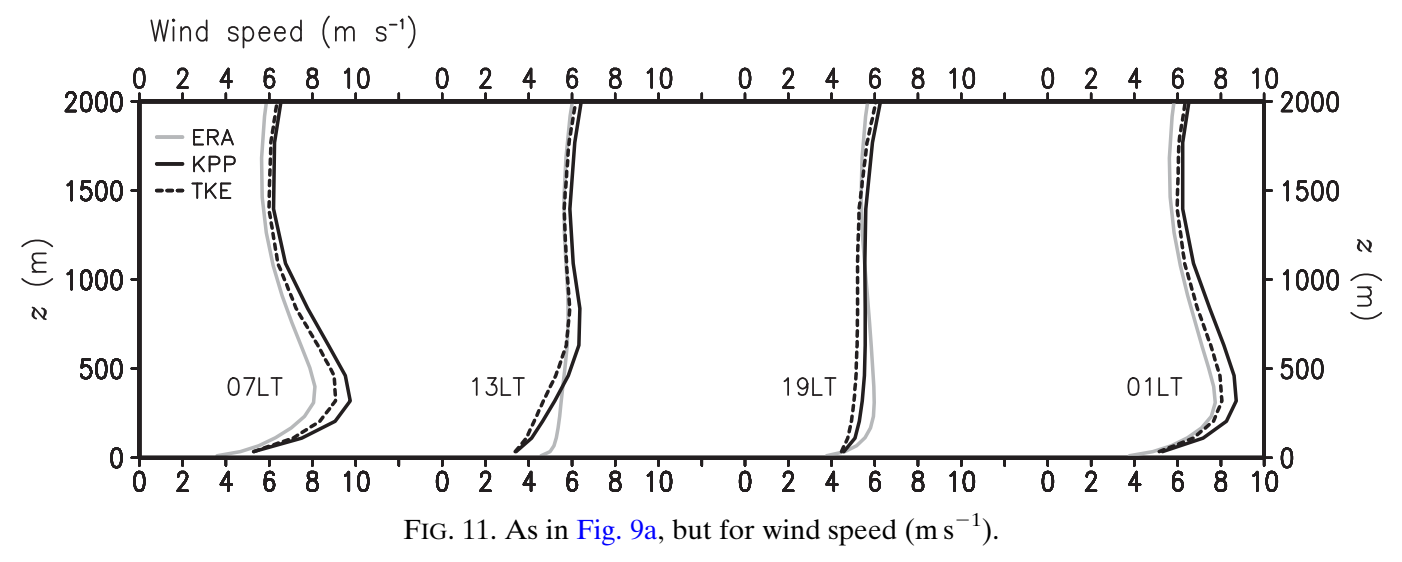


leading to the warmer daily maximum temperatures and larger diurnal amplitudes.

- The momentum transport from the nocturnal LLJs to the surfaces in the convective PBLs is underestimated in the models, and this accounts for the systematic underestimation of the near-surface winds.

This study is the first attempt at documenting the performance of GFDL AGCMs in the representation of the diurnal cycle climatologies of the PBL parameters, with the hope that it would give guidance in improving the PBL parameterization schemes. Based on the findings of this study, we plan to implement a countergradient (or gradient adjustment) transport term in the PBL schemes for increasing the vertical mixing in the convective PBLs and refine the vertical resolution in the surface layer for better resolving the stable PBLs.

It is noteworthy that the TKE PBL scheme showed the comparable performance to the KPP PBL scheme that has been the standard option in the GFDL AGCM for more than a decade. It was also found that the TKE scheme showed promise of improved stratocumulus simulations (not shown), justifying the continuous development of it in parallel with the standard option.

This is the first step toward a systematic evaluation of the two PBL schemes, and this study limited the analysis to the dry region over land. The differences between the two models in the simulated diurnal variations of the PBL were well explained by the vertical mixing processes in the region. However, the mixing processes are more complicated when clouds are involved in surfaceatmosphere interactions, and other sources in addition to the PBL scheme contribute to the biases. The largest cold biases in the Arctic, which is more severe in TKE than in KPP, are an example of the interactions. The temperature tendency profiles revealed that the main source of the colder temperatures in TKE is the excessive longwave radiative cooling near the surface by less downward longwave radiation, which is related in part to less low clouds. To understand such biases, further analysis for cloudy PBLs and interactions with convection and radiation are needed. More analysis on effects of horizontal resolution would be also helpful in understanding the model biases over mountainous areas and precipitation regions, considering the significant role of resolved topography and local/regional circulations in simulating the diurnal variability of moist processes (Lee et al. 2007; Dirmeyer et al. 2012; Bao and Zhang 2013b).

Acknowledgments. We thank Isaac Held and Levi Silvers for reviewing the manuscript and providing valuable comments. We also thank three anonymous referees for their constructive comments and suggestions. The first author is grateful to Jimy Dudhia and Jinho Yoon for their helpful comments. Work at LLNL was performed under the auspices of the U.S. Department of Energy by Lawrence Livermore National Laboratory under contract DE-AC52-07NA27344. MZ and BX are supported by NOAA's Climate Program Office, Climate Variability and Predictability Program (GC14-252).

\section{REFERENCES}

Arya, S. P., 2001: Introduction to Micrometeorology. Academic Press, $420 \mathrm{pp}$.

Bao, X., and F. Zhang, 2013a: Evaluation of NCEP-CFSR, NCEP-NCAR, ERA-Interim, and ERA-40 reanalysis datasets against independent sounding observations over the Tibetan Plateau. J. Climate, 26, 206-214, https://doi.org/ 10.1175/JCLI-D-12-00056.1.

_ and _ 2013b: Impacts of the mountain-plains solenoid and cold pool dynamics on the diurnal variation of warm-season precipitation over northern China. Atmos. Chem. Phys., 13, 6965-6982, https://doi.org/10.5194/acp-13-6965-2013.

Berrisford, P., and Coauthors, 2011: The ERA-Interim archive version 2.0. European Centre for Medium-Range Weather Forecasts ERA Report Series 1, 23 pp.

Betts, A. K., and C. Jakob, 2002: Evaluation of the diurnal cycle of precipitation, surface thermodynamics, and surface fluxes in the ECMWF model using LBA data. J. Geophys. Res., 107, 8045, https://doi.org/10.1029/2001JD000427.

Bretherton, C. S., J. R. McCaa, and H. Grenier, 2004: A new parameterization for shallow cumulus convection and its application to marine subtropical cloud-topped boundary layers. Part I: Description and 1D results. Mon. Wea. Rev., 132, 864-882, https://doi.org/10.1175/1520-0493(2004)132<0864: ANPFSC $>2.0 . \mathrm{CO} ; 2$.

Cuijpers, J. W. M., and P. G. Duynkerke, 1993: Large eddy simulation of trade wind cumulus clouds. J. Atmos. Sci., 50, 3894-3908, https://doi.org/10.1175/1520-0469(1993)050<3894: LESOTW $>2.0 . \mathrm{CO} ; 2$.

Decker, M., M. A. Brunke, Z. Wang, K. Sakaguchi, X. Zeng, and M. G. Bosilovich, 2012: Evaluation of the reanalysis products from GSFC, NCEP, and ECMWF using flux tower observations. J. Climate, 25, 1916-1944, https://doi.org/ 10.1175/JCLI-D-11-00004.1.

Dee, D. P., and Coauthors, 2011: The ERA-Interim reanalysis: Configuration and performance of the data assimilation system. Quart. J. Roy. Meteor. Soc., 137, 553-597, https://doi.org/ 10.1002/qj.828.

Dirmeyer, P. A., and Coauthors, 2012: Simulating the diurnal cycle of rainfall in global climate models: Resolution versus parameterization. Climate Dyn., 39, 399-418, https://doi.org/ 10.1007/s00382-011-1127-9.

Donner, L. J., and Coauthors, 2011: The dynamical core, physical parameterizations, and basic simulation characteristics of the atmospheric component of AM3 of the GFDL global coupled model CM3. J. Climate, 24, 3484-3519, https://doi.org/10.1175/ 2011JCLI3955.1.

ECMWF, 2013: Part IV: Physical processes. IFS Documentation CY38R1, European Centre for Medium-Range Weather Forecasts, 189 pp. 
Edwards, J. M., J. R. McGregor, M. R. Bush, and F. J. Bornemann, 2011: Assessment of numerical weather forecasts against observations from Cardington: Seasonal diurnal cycles of screen-level and surface temperatures and surface fluxes. Quart. J. Roy. Meteor. Soc., 137, 656-672, https://doi.org/ 10.1002/qj.742.

Gallée, H., and Coauthors, 2015: Characterization of the boundary layer at Dome C (East Antarctica) during the OPALE summer campaign. Atmos. Chem. Phys., 15, 6225-6236, https://doi.org/ 10.5194/acp-15-6225-2015.

Galperin, B., L. H. Kantha, S. Hassid, and A. Rosati, 1988: A quasi-equilibrium turbulent energy model for geophysical flows. J. Atmos. Sci., 45, 55-62, https://doi.org/10.1175/ 1520-0469(1988)045<0055:AQETEM>2.0.CO;2.

Garner, S. T., 2005: A topographic drag closure built on an analytical base flux. J. Atmos. Sci., 62, 2302-2315, https://doi.org/ 10.1175/JAS3496.1.

Garratt, J. R., 1992: The Atmospheric Boundary Layer. Cambridge University Press, 319 pp.

Hartmann, D. L., 1994: Global Physical Climatology. Academic Press, $411 \mathrm{pp}$.

Heymsfield, A. J., and L. J. Donner, 1990: A scheme for parameterizing ice-cloud water content in general circulation models. J. Atmos. Sci., 47, 1865-1877, https://doi.org/10.1175/ 1520-0469(1990)047<1865:ASFPIC > 2.0.CO;2.

Holtslag, A. A. M., and B. A. Boville, 1993: Local versus nonlocal boundary-layer diffusion in a global climate model. J. Climate, $\mathbf{6}$, 1825-1842, https://doi.org/10.1175/1520-0442(1993)006<1825: LVNBLD $>2.0 . \mathrm{CO} ; 2$.

- and Coauthors, 2013: Stable atmospheric boundary layers and diurnal cycles: Challenges for weather and climate models. Bull. Amer. Meteor. Soc., 94, 1691-1706, https://doi.org/10.1175/ BAMS-D-11-00187.1.

Hong, S.-Y., and H.-L. Pan, 1996: Nonlocal boundary layer vertical diffusion in a medium-range forecast model. Mon. Wea. Rev., 124, 2322-2339, https://doi.org/10.1175/1520-0493(1996)124<2322: NBLVDI $>2.0 . \mathrm{CO} ; 2$.

Hourdin, F., and Coauthors, 2017: The art and science of climate model tuning. Bull. Amer. Meteor. Soc., 98, 589-602, https:// doi.org/10.1175/BAMS-D-15-00135.1.

Hu, X.-M., J. W. Nielsen-Gammon, and F. Zhang, 2010: Evaluation of three planetary boundary layer schemes in the WRF Model. J. Appl. Meteor. Climatol., 49, 1831-1844, https://doi.org/ 10.1175/2010JAMC2432.1.

Lee, M.-I., and Coauthors, 2007: Sensitivity to horizontal resolution in the AGCM simulations of warm season diurnal cycle of precipitation over the United States and northern Mexico. J. Climate, 20, 1862-1881, https://doi.org/10.1175/ JCLI4090.1.

Lin, S.-J., 1997: A finite-volume integration method for computing pressure gradient force in general vertical coordinates. Quart. J. Roy. Meteor. Soc., 123, 1749-1762, https://doi.org/10.1002/ qj. 49712354214.

__ 2004: A "vertically Lagrangian" finite-volume dynamical core for global models. Mon. Wea. Rev., 132, 2293-2307, https://doi.org/ 10.1175/1520-0493(2004)132<2293:AVLFDC >2.0.CO;2.

—_, and R. B. Rood, 1996: Multidimensional flux-form semiLagrangian transport schemes. Mon. Wea. Rev., 124, 20462070, https://doi.org/10.1175/1520-0493(1996)124<2046: MFFSLT $>2.0 . \mathrm{CO} ; 2$.

, and _- 1997: An explicit flux-form semi-Lagrangian shallow-water model on the sphere. Quart. J. Roy. Meteor. Soc., 123, 2477-2498, https://doi.org/10.1002/qj.49712354416.
Lin, X., D. A. Randall, and L. D. Fowler, 2000: Diurnal variability of the hydrologic cycle and radiative fluxes: Comparison between observations and a GCM. J. Climate, 13, 4159-4179, https://doi.org/10.1175/1520-0442(2000)013<4159: DVOTHC $>2.0 . \mathrm{CO} ; 2$.

Lindsay, R., M. Wensnahan, A. Schweiger, and J. Zhang, 2014: Evaluation of seven different atmospheric reanalysis products in the Arctic. J. Climate, 27, 2588-2606, https://doi.org/10.1175/ JCLI-D-13-00014.1.

Lindvall, J., G. Svensson, and C. Hannay, 2013: Evaluation of nearsurface parameters in the two versions of the atmospheric model in CESM1 using flux station observations. J. Climate, 26, 26-44, https://doi.org/10.1175/JCLI-D-12-00020.1.

Liu, S., and X.-Z. Liang, 2010: Observed diurnal cycle climatology of planetary boundary layer height. J. Climate, 23, 5790-5809, https://doi.org/10.1175/2010JCLI3552.1.

Lock, A. P., 1998: The parameterization of entrainment in cloudy boundary layers. Quart. J. Roy. Meteor. Soc., 124, 2729-2753, https://doi.org/10.1002/qj.49712455210.

— , A. R. Brown, M. R. Bush, G. M. Martin, and R. N. B. Smith, 2000: A new boundary layer mixing scheme. Part I: Scheme description and single-column model tests. Mon. Wea. Rev., 128, 3187-3199, https://doi.org/10.1175/1520-0493(2000)128<3187: ANBLMS $>2.0 . \mathrm{CO} ; 2$.

Loeb, N. G., B. A. Wielicki, D. R. Doelling, G. L. Smith, D. F. Keyes, S. Kato, N. Manalo-Smith, and T. Wong, 2009: Toward optimal closure of the earth's top-of-atmosphere radiation budget. J. Climate, 22, 748-766, https://doi.org/10.1175/ 2008JCLI2637.1.

Louis, J.-F., 1979: A parametric model of vertical eddy fluxes in the atmosphere. Bound.-Layer Meteor., 17, 187-202, https://doi.org/ 10.1007/BF00117978.

Marsham, J. H., and Coauthors, 2013: Meteorology and dust in the central Sahara: Observations from Fennec supersite-1 during the June 2011 intensive observation period. J. Geophys. Res. Atmos., 118, 4069-4089, https://doi.org/ 10.1002/jgrd.50211.

McGrath-Spangler, E. L., and A. Molod, 2014: Comparison of GEOS-5 AGCM planetary boundary layer depths compared with various definitions. Atmos. Chem. Phys., 14, 6717-6727, https://doi.org/10.5194/acp-14-6717-2014.

Mellor, G. L., and T. Yamada, 1974: A hierarchy of turbulence closure models for planetary boundary layers. J. Atmos. Sci., 31, 1791-1806, https://doi.org/10.1175/1520-0469(1974)031<1791: AHOTCM $>2.0$.CO;2.

$\longrightarrow$, and 1982: Development of a turbulence closure model for geophysical fluid problems. Rev. Geophys., 20, 851-875, https://doi.org/10.1029/RG020i004p00851.

Poli, P., and Coauthors, 2016: ERA-20C: An atmospheric reanalysis of the twentieth century. J. Climate, 29, 4083-4097, https://doi.org/10.1175/JCLI-D-15-0556.1.

Rienecker, M. M., and Coauthors, 2011: MERRA: NASA's Modern-Era Retrospective Analysis for Research and Applications. J. Climate, 24, 3624-3648, https://doi.org/10.1175/ JCLI-D-11-00015.1.

Rotstayn, L. D., B. F. Ryan, and J. J. Katzfey, 2000: A scheme for calculation of the liquid fraction in mixed-phase stratiform clouds in large-scale models. Mon. Wea. Rev., 128, 1070-1088, https://doi.org/10.1175/1520-0493(2000)128<1070: ASFCOT $>2.0 . \mathrm{CO} ; 2$.

Saha, S., and Coauthors, 2010: The NCEP Climate Forecast System Reanalysis. Bull. Amer. Meteor. Soc., 91, 1015-1058, https:// doi.org/10.1175/2010BAMS3001.1. 
Seidel, D. J., Y. Zhang, A. Beljaars, J.-C. Golaz, A. R. Jacobson, and B. Medeiros, 2012: Climatology of the planetary boundary layer over the continental United States and Europe. J. Geophys. Res., 117, D17106, https://doi.org/10.1029/ 2012JD018143.

Shin, H. H., and S.-Y. Hong, 2011: Intercomparison of planetary boundary-layer parametrizations in the WRF Model for a single day from CASES-99. Bound.-Layer Meteor., 139, 261281, https://doi.org/10.1007/s10546-010-9583-z.

Steeneveld, G. J., T. Mauritsen, E. I. F. de Bruijn, J. V.-G. de Arellano, G. Svensson, and A. A. M. Holtslag, 2008: Evaluation of limitedarea models for the representation of the diurnal cycle and contrasting nights in CASES-99. J. Appl. Meteor. Climatol., 47, 869-887, https://doi.org/10.1175/2007JAMC1702.1.

Stull, R. B., 1988: An Introduction to Boundary Layer Meteorology. Kluwer Academic, 666 pp.

Svensson, G., and J. Lindvall, 2015: Evaluation of near-surface variables and the vertical structure of the boundary layer in CMIP5 models. J. Climate, 28, 5233-5253, https://doi.org/ 10.1175/JCLI-D-14-00596.1.

_ - and Coauthors, 2011: Evaluation of the diurnal cycle in the atmospheric boundary layer over land as represented by a variety of single-column models: The second GABLS experiment. Bound.-Layer Meteor., 140, 177-206, https://doi.org/ 10.1007/s10546-011-9611-7.

Teixeira, J., and Coauthors, 2008: Parameterization of the atmospheric boundary layer: A view from just above the inversion. Bull. Amer. Meteor. Soc., 89, 453-458, https://doi.org/10.1175/ BAMS-89-4-453.
Tiedtke, M., 1993: Representation of clouds in large-scale models. Mon. Wea. Rev., 121, 3040-3061, https://doi.org/10.1175/ 1520-0493(1993)121<3040:ROCILS > 2.0.CO;2.

Troen, I. B., and L. Mahrt, 1986: A simple model of the atmospheric boundary layer; sensitivity to surface evaporation. Bound.-Layer Meteor., 37, 129-148, https://doi.org/10.1007/ BF00122760.

von Engeln, A., and J. Teixeira, 2013: A planetary boundary layer height climatology derived from ECMWF reanalysis data. J. Climate, 26, 6575-6590, https://doi.org/10.1175/JCLI-D-12-00385.1.

Wyngaard, J. C., 2010: Turbulence in the Atmosphere. Cambridge University Press, $393 \mathrm{pp}$

Zhang, D.-L., and W.-Z. Zheng, 2004: Diurnal cycles of surface winds and temperatures as simulated by five boundary layer parameterizations. J. Appl. Meteor., 43, 157-169, https://doi.org/ 10.1175/1520-0450(2004)043<0157:DCOSWA > 2.0.CO;2.

Zhao, M., I. M. Held, S.-J. Lin, and G. A. Vecchi, 2009: Simulations of global hurricane climatology, interannual variability, and response to global warming using a $50-\mathrm{km}$ resolution GCM. J. Climate, 22, 6653-6678, https://doi.org/10.1175/ 2009JCLI3049.1.

- and Coauthors, 2018a: The GFDL global atmosphere and land model AM4.0/LM4.0: 1. Simulation characteristics with prescribed SSTs. J. Adv. Model. Earth Syst., 10, 691-734, https://doi.org/10.1002/2017MS001208.

— , and Coauthors, 2018b: The GFDL global atmosphere and land model AM4.0/LM4.0: 2. Model description, sensitivity studies, and tuning strategies. J. Adv. Model. Earth Syst., 10, 735-769, https://doi.org/10.1002/2017MS001209. 